\title{
Design of Al-Ce Alloys for Laser Additive Manufacturing Evaluation of an Al-Ce Alloy for Laser Additive Manufacturing
}

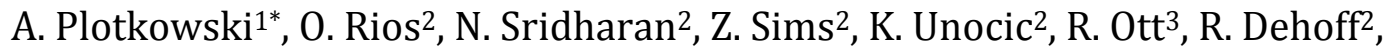 \\ and S. S. Babu ${ }^{1,2}$
}

${ }^{1}$ University of Tennessee - Knoxville, Knoxville, TN

${ }^{2}$ Oak Ridge National Laboratory, Oak Ridge, TN

${ }^{3}$ Ames National Laboratory, Ames, IA

*Corresponding author

Email: aplotkow@utk.edu

Phone: 616-350-5947

Address: 1512 Middle Drive

Knoxville, TN 37996

\begin{abstract}
Present research in metal additive manufacturing (AM) focuses on designing processing parameters around existing alloys designed for traditional manufacturing. However, to maximize the benefits of $A M$, alloys should be designed to specifically take advantage of the unique thermal conditions of these processes. This study focuses on the development of a design methodology for alloys in AM, using a newly developed Al-Ce alloy as an initial case study. To evaluate the candidacy of this system for fusion based additive manufacturing directed energy deposition processes, single-line laser melts were made on cast $\mathrm{Al}-12 \mathrm{Ce}$
\end{abstract}


plates using three different beam velocities $(100,200$, and $300 \mathrm{~mm} / \mathrm{min})$. The microstructure was evaluated in the as-melted and heat treated conditions ( $24 \mathrm{hrs}$ at 300 ${ }^{\circ} \mathrm{C}$ ). An extremely fine microstructure was observed within the weld pools, evolving from eutectic at the outer solid-liquid boundaries to a primary Al FCC dendritic/cellular structure nearer the melt-pool centerline. The observed microstructures were rationalized through the construction of a microstructure selection map for the Al-Ce binary system, which will be used to enable future alloy design. Interestingly, the heat treated samples exhibited no microstructural coarsening.

Keywords: Additive manufacturing; Al alloys; Microstructure control; Microstructure modeling

\subsection{Introduction}

Metal additive manufacturing (AM) presents many opportunities through its ability to manufacture components with complex geometries and site-specific manipulation of thermal conditions to control the microstructure [1]. AM also presents unique challenges, such as the difficulty in producing dense parts from metal powders, controlling hot cracking, swelling and other defects, property anisotropy related to textural effects, and compositional changes due to preferred vaporization of volatile elements [2]. The majority of research in metal AM has focused on process optimization for alloys that were originally designed for traditional manufacturing routes. However, alloy selection in this manner will generally compromise on material properties in favor of minimizing defect development during processing. In order to advance metal AM technologies while maintaining target 
properties, it will be necessary to design alloy compositions that mitigate these processing challenges. However, a major barrier to alloy design for AM is the procurement of powder of various compositions other than those that are already commercially available. In this paper, we outline an alloy design evaluation methodology that uses using laser melting and existing microstructure development theory to identify compositions suitable understand the solidification structures that are produced within the processing range for directed energy deposition (DED) processes for AM. DED processes use a laser to melt powder that is fed by a coaxial nozzle in an inert carrier gas, and are generally operated at lower velocities than powder bed systems. This range of processing conditions is also relevant to laser welding and laser surface processes. This-The proposed methodology was evaluated within validated through application to a recently developed casting alloy in the Al-Ce binary system.

Previous research by Sims et al. [3] demonstrated the potential for Ce as the primary alloying element in a new series of $\mathrm{Al}$ casting alloys. While Ce is the most abundant of the rare earth metals, it is only considered a by-product of rare earth mining efforts due to a lack of high-volume applications. As a result, it is relatively inexpensive as an alloying element. In the phase diagram (Figure 1) for the Al-Ce system, as determined using computational thermodynamics [4], a wide range of compositions between pure Al and the $\mathrm{Al}_{11} \mathrm{Ce}_{3}$ intermetallic are possible, featuring a eutectic point at $\mathrm{Al}-10 \mathrm{Ce}$ (all compositions given in weight percent) and $640^{\circ} \mathrm{C}$. The solubility of $\mathrm{Al}$ in the intermetallic and $\mathrm{Ce}$ in $\mathrm{Al}$ are negligible, and previous work in both powder metallurgy [5] and casting $[3,6]$ has shown that Al-Ce based alloys exhibit excellent thermal stability, maintaining a high percentage of 
room temperature strength up to at least $250^{\circ} \mathrm{C}$. The small freezing range of near-eutectic compositions (Sims et al. tested Al-12Ce) also display excellent fluidity and castability [3] and is expected to reduce hot-tearing [7]. Compared to as-cast near-eutectic Al-Si alloys modified by $\mathrm{Sr}$ [8], the as-cast Al-12Ce binary alloy demonstrated similar yield strength (57 $\mathrm{MPa})$, ultimate tensile strength (161 MPa) and elongation (13.5\%) values. A T6 heat treatment tended to decrease the UTS and yield strength by approximately $20 \%$, but nearly doubled ductility to $26.5 \%$. Additions of Si and Mg (Al-12Ce-4Si-0.4Mg) increased the yield strength (75 MPa), slightly decreased the as-cast UTS (141 MPa) and significantly decreased elongation (2\%), but allowed for precipitation hardening that, upon T6 heat treatment, obtained a yield strength of $128.2 \mathrm{MPa}$, a UTS of $252.3 \mathrm{MPa}$, and improved the elongation to $8.5 \%$, values which are competitive with commercial aluminum alloys such as A356. Due to their exceptional thermal stability, Al-Ce alloys shows promise for high temperature, weight-critical applications such as automotive engines. Al alloys currently used for such applications maintain only a small fraction $(<25 \%)$ of their room temperature tensile properties after exposure to temperatures exceeding $300{ }^{\circ} \mathrm{C}[9,10]$. AlCe alloys may be stable at similar elevated temperatures, and possibly higher, and given their excellent thermal stability and good castability, are good candidates for additive manufacturing.

In designing a new alloy for AM, there are a variety of challenges and opportunities. Chief amongst these is understanding the effect of non-equilibrium cooling conditions and thermal cycling on microstructural development [11]. The large thermal gradients $(G)$ and solidification interface velocities $(V)$ found within the weld pool are far from those typical 
of castings. These variations are a functions of material (thermal conductivity, density, specific heat capacity, and thermodynamic parameters) and process parameters including beam power, beam velocity, spot size, part geometry, and the chosen scan strategy. Rapid These solidification conditions may result in exceedingly fine microstructures and the formation of non-equilibrium phase selection and alloying element partitioning. Through the manipulation of process parameters, it is sometimes possible to control microstructural features through changes in the local $V$ and $G$ [12-14]. For example, Dehoff et al. [15] manipulated used differentscan strategy ies parameter in electron beam melting of IN718 to selectively grow equiaxed grains within a columnar microstructure. Given these exciting results, future work should seek to control other aspects of the microstructure such as selecting particular phases, modifying phase or grain morphologies, or controlling precipitation behavior. To maintain these structures during processing however, the alloy in question must also resist coarsening during the thermal cycling that occurs as a result of melting neighboring material and subsequent layers. Ideally, alloys would be designed which are compatible with these processing characteristics instead of relying on existing compositions originally designed for very different processing conditions.

The objective of the present research is to use laser melting of a bare plate as a method for approximating the and its rapid cooling conditions found in DED processes to show that AM components made with Al-Ce alloys can achieve mechanical properties superior to their cast counterparts, and to explore the design space offered by process-microstructure correlations. First, the hardness of the laser welded melted regions were compared to the as-cast structure, including a heat treatment study intended to imitate prolonged use at 
elevated temperature either during end-user application or as a result of thermal cycling during processing. The microstructure in the weld region was evaluated and differences in structure were rationalized by constructing an approximate microstructure selection map based on non-equilibrium theory for planar, dendritic, and eutectic growth. This map was then used to project the ability of the alloy's structure and properties to be tailored via process parameter manipulation.

\subsection{Experimental Procedure}

The suitability of a hypereutectic Al-12Ce alloy for AM was investigated using single-line laser melts on a flat plate. The plate was machined from a cast ingot with composition prepared by alloying liquid $\mathrm{Al}$ at $750^{\circ} \mathrm{C}$ with the appropriate amount of Ce. Small plates were machined from the resulting ingots, and the surface was grit blasted to improve laser absorption. To make the single-line laser melts, a diode laser with a $910 \mathrm{~nm}$ wavelength and $1.5 \mathrm{~mm}$ spot size was used. A laser power of $800 \mathrm{~W}$ was used with three different beam velocities in an argon atmosphere. A summary of these cases are given in Table 1. The selection of these process parameters is meant to mimic the conditions present in directed energy deposition (DED) processes, whereas powder bed fusion (PBF) processes tend to use smaller spot sizes and higher velocities [16]. To assess the thermal stability of the laser melted microstructure during service, samples were heat treated at $300^{\circ} \mathrm{C}$ for $24 \mathrm{hr}$. Following processing, samples were sectioned on the plane normal to the beam travel direction, polished, and etched using a highly diluted Keller's reagent. Optical and scanning electron microscopy was used to characterize the microstructure was then characterized 
and ImageJ was used for measurements of the eutectic spacing. Vickers microhardness was used to characterize the difference in mechanical properties between the as-cast material and the laser welded microstructure and as a function of heat treatment. TEM lamella were prepared via the focused-ion-beam (FIB) in situ lift-out technique using a Hitachi NB5000 FIB-SEM, and were examined by S/TEM using an FEI Talos F200X operated at $200 \mathrm{kV}$ and equipped with an extreme field emission gun (X-FEG) electron source and super-X EDS (energy-dispersive spectroscopy) system with 4 silicon drift detectors (SDD) for chemical analysis.

Table 1: Design matrix for examining the weldability of two Al-Ce alloys under various laser power and beam velocity conditions (all composition values are in weight percent).

\begin{tabular}{|l|lll|}
\hline Composition & $\begin{array}{l}\text { Sample } \\
\text { number }\end{array}$ & $\begin{array}{l}\text { Laser } \\
\text { Power (W) }\end{array}$ & $\begin{array}{l}\text { Beam Velocity } \\
\text { (mm/min) }\end{array}$ \\
\hline \multirow{3}{*}{ Al-12Ce } & B7 & 800 & 100 \\
& B8 & 800 & 200 \\
& B9 & 800 & 300 \\
\hline
\end{tabular}

\subsection{Theoretical Calculations}

\subsection{Background Literature}

In order to understand the effect of local variations in solidification conditions within the weld pool and as a function of the beam velocity and alloy composition, non-equilibrium growth theory was used to develop a microstructure selection map for Al-Ce alloys. The basis of this approach is to predict the interfacial growth temperature for each of a variety of microstructures, and the dominant structure is the one that has the highest growth 
temperature for those conditions. The theories described by Kurz, Giovanola, and Trivedi [17] for dendritic growth and Kurz and Trivedi [18] for eutectic growth were implemented in this model. The microstructures under consideration are the eutectic $\mathrm{Al}_{-} \mathrm{Al}_{11} \mathrm{Ce}_{3}$ structure, dendritic/cellular growth for either primary $\mathrm{Al}_{\text {or }} \mathrm{Al}_{11} \mathrm{Ce}_{3}$, planar front growth for the two phases, and banded structures that oscillated between planar and dendritic growth. The output of this model is the active growth mode for a given set of interface growth velocity, thermal gradient, and alloy composition. In addition, the eutectic spacing is predicted as a function of interface growth velocity. The details of the model and its implementation are summarized in the appendix.

\subsection{Selection of Material Properties and Model Sensitivity}

Due to limited literature on the Al-Ce system, there was considerable difficulty in selecting material properties for use in calculating the microstructure selection map. Some parameters, such as melting temperatures $\left(T_{m, \alpha}\right.$ and $\left.T_{m, \beta}\right)$, equilibrium partition coefficients ( $k_{\alpha}$ and $k_{\beta}$ ), liquidus slopes ( $m_{\alpha}$ and $m_{\beta}$ ), and phase volume fractions in the eutectic $\left(f_{\beta}\right)$ could be determined from the calculated phase diagram. For the remaining parameters, values for the Al-Si system were used, including the Gibbs-Thomson coefficients $\left(\Gamma_{\alpha}\right.$ and $\left.\Gamma_{\beta}\right)$, contact angles with the liquid $\left(\theta_{\alpha}\right.$ and $\left.\theta_{\beta}\right)$, and the mass diffusivity in the liquid $(D)$. The rational for these choices is loosely based on microstructures reported by Sims et al. [6]. In those micrographs, primary $\mathrm{Al}_{11} \mathrm{Ce}_{3}$ were not observed in $\mathrm{Al}$ 12Ce alloys (slightly hypereutectic), and in $\mathrm{Al}-16 \mathrm{Ce}$, primary $\mathrm{Al}_{11} \mathrm{Ce}_{3}$ particles exhibited faceted shapes. These observations are consistent with the highly anisotropic behavior of primary Si particles in hypereutectic Al-Si alloys which causes the existence of a skewed 
coupled zone below the equilibrium eutectic temperature [19]. Similar phenomena in the Al-Ce system would explain the absence of primary $\mathrm{Al}_{11} \mathrm{Ce}_{3}$ at compositions above the eutectic point. Because of these similarities, and on a more practical note, because data for $\mathrm{Al}-\mathrm{Si}$ is easily available, properties were approximated from Al-Si when not determined from the Al-Ce phase diagram (as summarized in Table 2). In the subsequent model results, the only data that deviates from either the Al-Ce phase diagram or Al-Si properties is the mass diffusivity in the liquid. The fine eutectic and high thermal stability of the $\mathrm{Al}^{-} \mathrm{Al}_{11} \mathrm{Ce}_{3}$ structure suggests either very slow mass diffusion or a particularly low interface energy (manifested in the Gibbs-Thomson coefficient). To approximate this behavior, a diffusivity value has been estimated for use in calculating the microstructure selection maps and eutectic spacing.

Table 2: Material properties used for microstructural models.

\begin{tabular}{|c|c|c|c|}
\hline \multicolumn{2}{|c|}{ From Al-Ce Phase Diagram } & \multicolumn{2}{|c|}{ From Al-Si System [19] } \\
\hline$C_{E}$ & 10.0 wt. $\% \mathrm{Ce}$ & $\Gamma_{\alpha}$ & $0.9 \times 10^{-7} \mathrm{mK}$ \\
\hline$C_{\beta}$ & 58.6 wt. $\% \mathrm{Ce}$ & $\Gamma_{\beta}$ & $2.0 \times 10^{-7} \mathrm{mK}$ \\
\hline$T_{m, \alpha}$ & $660.3^{\circ} \mathrm{C}$ & $\theta_{\alpha}$ & $25.0^{\circ}$ \\
\hline$T_{m, \beta}$ & $1235^{\circ} \mathrm{C}$ & $\theta_{\beta}$ & $85.0^{\circ}$ \\
\hline$k_{\alpha}$ & $6.49 \times 10^{-11}$ & $D$ & $3 \times 10^{-9}$ \\
\hline$k_{\beta}$ & $4.33 \times 10^{-11}$ & & $1 \times 10^{-9}$ \\
\hline$f_{\beta}$ & 0.0976 & $\begin{array}{l}\text { (Estimated } \\
\text { for Al-Ce) }\end{array}$ & \\
\hline
\end{tabular}

Given the unknown nature of many of these parameter values for the Al-Ce system, the authors would like to stress that the resulting microstructural maps are strictly approximations. Here, they will be used to explain trends seen in the microstructural 
development during laser melting, but accurate quantitative predictions should not be expected until improved material data becomes available. Therefore, before considering the results of the microstructure selection model, it is important to address the model's sensitivity to parametric approximations. The simplest quantitative result of the model is the prediction of the eutectic spacing. A crude local sensitivity analysis was performed by varying each of a variety of inputs by $\pm 10 \%$ from their nominal values for a beam velocity of $200 \mathrm{~mm} / \mathrm{min}$. The predicted lamellar spacing for the nominal values was $0.463 \mu \mathrm{m}$. The fraction difference in the predicted lamellar spacing for the given variation in each input is shown in Figure 2. Clearly, the mass diffusivity, the Gibbs-Thomson coefficient for $\mathrm{Al}_{11} \mathrm{Ce}_{3}$ and the liquidus slope for $\mathrm{Al}_{11} \mathrm{Ce}_{3}$ have the greatest effect on the lamellar spacing. The liquidus slope is the least important of these three inputs because it can be determined with reasonable accuracy from the thermodynamic data. The mass diffusivity and GibbsThomson coefficient however both greatly impact the spacing prediction and are also not well known. On the other hand, the contact angles between the solid phases and the liquid and the Gibbs-Thomson coefficient for Al have a comparatively minor influence on the eutectic model. Moreover, because of their extremely small values in the Al-Ce system, changes in the partition coefficients have essentially no effect on the eutectic spacing. These results highlight the approximate nature of the eutectic predictions and the microstructure selection map. Future efforts to improve the predictive ability of these models for the Al-Ce system should focus on determining accurate values for $D$ and $\Gamma_{\beta}$.

\subsection{Laser Welding Melting Results}

\subsection{Weld Melt Pool Microstructure}


For all the process parameters tested, no cracking or significant porosity was observed. Figure 3 shows a comparison of the melt pools for the three beam velocities. As the beam velocity increased, the width of the poold decreased by approximately $4 \%$. A higher magnification of the weld microstructure is shown in Figure 4 for the slowest beam velocity of $100 \mathrm{~mm} / \mathrm{min}$. Within the laser melted region, three different microstructures are present. Near the edge of the weld pool where the interface growth velocity is low and thermal gradient high [20], the microstructure is entirely eutectic. Moving inward towards the center of the weld pool, the interface growth velocity increases and thermal gradient decreases, causing instabilities in the eutectic growth before the microstructure shifts to a dendritic/cellular Al growth with a fine eutectic structure in the interdendritic/intercellular region. Outside of the laser melted region, note the lack of any significant microstructural changes in the heat affected zone (HAZ). This observation is consistent with the high temperature stability reported by Sims et al. [6].

Figure 5 shows higher magnification views of these three regions for all three beam velocities. The primary difference between the three cases is the spacing in the eutectic structure at the outer radius of the laser melted region. In addition, as shown in Figure 6, the thickness of the fully eutectic region at the outer radius of the weld pool tended to decreased with increasing beam velocity. Similar to the results given by Sims et al. [6], no primary $\mathrm{Al}_{11} \mathrm{Ce}_{3}$ particles were found in the hypereutectic $\mathrm{Al}-12 \mathrm{Ce}$ microstructures (although they did begin to see primary $\mathrm{Al}_{11} \mathrm{Ce}_{3}$ in cast microstructures for $\mathrm{Al}-16 \mathrm{Ce}$ alloys). Instead, primary Al was observed for all cases. 


\subsection{Heat Treated Microstructure}

To establish the thermal stability of the ultra-fine microstructure observed in the laser melted samples, the material was heat treated at the target operating temperature of $300^{\circ} \mathrm{C}$ for 24 hrs. The microstructure of the heat treated samples are shown in Figure 7. Again, near the outer radius of the melt pool, a eutectic structure is observed, which becomes unstable as the interface growth velocity increases towards the center $\theta$ f the weld, eventually resulting in a primary $\mathrm{Al}$ dendritic/cellular structure. As compared to the asmelted structures in Figure 5, there appears to be no significant coarsening of the microstructure. A complete comparison of the differences in length scales across these conditions (as-cast, as-melted, and heat treated) are shown in Figure 8 for a beam velocity of $300 \mathrm{~mm} / \mathrm{min}$, including a high magnification of the fine rod-like eutectic structure at the edge of the meld mool.

\subsection{Hardness Results}

Vickers micro-hardness results for the $200 \mathrm{~mm} / \mathrm{min}$ beam velocity in both the as-melted and heat treated conditions are shown as a histogram in Figure 9. The distributions are predominantly bimodal, showing a collection of moderate hardness values corresponding to the cast material, and peaks at higher hardness values for the laser melted regions. For the as-melted condition, the hardness in the weld pool is significantly higher than that in the cast material. The cast microstructure exhibits hardness of approximately 40-50 HVN, while the fine microstructure in the weld pool increased to about 60-70 HVN, marking about a $30-40 \%$ increase. Some areas of extremely low hardness in the cast material are due to porosity. Similar trends in hardness are found for the heat treated condition (Figure 
9c). The heat treated sample shows a slightly higher hardness in the laser melted region, but this is likely caused by minor process variations. The higher hardness also corresponds to a slightly finer eutectic (quantified in section 5.1). The distributions of hardness values are shown in the histogram in Figure 10. The distributions are predominantly bimodal, showing a collection of moderate hardness values corresponding to the cast material, and peaks at higher hardness values for the laser melted regions. Several very low data points caused by porosity are also vident.

\subsection{Comparison with Microstructural Models}

\subsection{Eutectic Growth}

The predictions of eutectic spacing from the eutectic growth model were compared to measurements from the laser melted samples at various beam velocities. Experimental measurements taken from the fully eutectic region at the outer radius of the weld pools are shown in Figure 1110 for both the as-melted and heat treated conditions, where the vertical errors bars indicate \pm 2 standard deviations in the eutectic spacing measurements. The relevant velocity that governs solidification kinetics is the interfacial growth velocity, which varies throughout the melt pool as a function of the beam velocity and the angle between the beam direction and the local growth vector [21]. Since this information is not known for each of the measurements taken, horizontal error bars are shown which vary from the maximum velocity (the beam velocity) to an interface growth velocity for a $45^{\circ}$ angle between the growth direction and beam direction. Note that the eutectic spacing (when considering the experimental variation) did not coarsen in the heat treated samples. The particularly small eutectic spacing observed for the heat treated sample at a beam 
velocity of $200 \mathrm{~mm} / \mathrm{min}$ was likely due to process inhomogeneities as it corresponded with a small observed region of local remelting. Otherwise, the eutectic measurements are identical between the two conditions. The eutectic spacing for all cases fell between approximately 0.2 and $0.8 \mu \mathrm{m}$, which is small compared to the cast structure which had an average spacing of $1.7 \mu \mathrm{m}$, with a wide standard deviation of $1.08 \mu \mathrm{m}$.

Also, given the results of the sensitivity analysis shown in Figure 2, the model results for the approximated $\mathrm{Al}-\mathrm{Ce}$ properties are compared to those predicted for $\mathrm{Al}-\mathrm{Si}$ under the same solidification conditions. The Al-Si properties are well understood, suggesting that, since the model predictions fall uniformly above the experimentally observed eutectic spacing for each beam velocity, the model is at least accurate enough to differentiate between the $\mathrm{Al}-\mathrm{Si}$ and $\mathrm{Al}-\mathrm{Ce}$ alloys even considering the uncertainty in the $\mathrm{Al}-\mathrm{Ce}$ properties. Based on the available data, it appears that a reduced mass diffusivity $\left(10^{-9} \mathrm{~m}^{2} / \mathrm{s}\right)$ compared to that of $\mathrm{Al}-\mathrm{Si}$ is a reasonable conclusion when comparing both the thermal stability of the microstructure and the eutectic growth. In eutectic growth, this difference in diffusivity manifests as a change in the diffusion distance over which solute transport occurs during the coupled $\mathrm{Al}$ and $\mathrm{Al}_{11} \mathrm{Ce}_{3}$ growth. However, this general conclusion should not be mistaken for an accurate determination of the mass diffusivity due to significant uncertainty in other input parameter (Gibbs-Thomson coefficients and contact angles) that were held constant during this analysis and play a role in the determination of eutectic spacing during coupled growth through interface curvature effects. These curvature effects may also have a significant effect on the coarsening kinetics in the Al-Ce system. In general, 
an increase in the Gibbs-Thomson coefficient will tend to increase both the eutectic spacing and the rate of coarsening.

\subsection{Variations in Microstructure Throughout the Weld Pool}

The microstructural maps generated using the procedure outlined in the appendix are shown in Figure 12 11. The plots are generated over a range of compositions and interface velocities for a constant thermal gradient of $10^{6} \mathrm{~K} / \mathrm{m}$. In the present case, microstructure selection is much less sensitive to thermal gradient than to either interface growth velocity or composition, so $10^{6} \mathrm{~K} / \mathrm{m}$ was chosen as an average based on numerical calculations of laser processes in the literature wherein the thermal gradient ranges from approximately $10^{4}$ to $10^{8} \mathrm{~K} / \mathrm{m}$ [22]. By looking at the effect of composition, the intention is to enable microstructure selection through alloy design.

There are several interesting features to note in Figure 12 in relationship to the microstructures presented above. First, Figure 12 11a shows the map for a mass diffusivity in the liquid of $10^{-9} \mathrm{~m}^{2} / \mathrm{s}$, which, as shown in Figure 1110 , gives a reasonable prediction of the eutectic spacing. However, in the case of the microstructure selection map, the approximate range of interface growth velocities expected for the process parameters used does not predict the range of microstructures observed experimentally (indicated by the white arrow overlaid on the plot). For this set of property values, the model predicts that only eutectic growth should be stable, which is clearly not the case when observing the microstructures present in the laser melted regions in Figure 4. Given the uncertain nature of several of the properties used in the present model, it is possible to force the model to 
match the observed results. By changing the mass diffusivity to an extremely small value $\left(10^{-11} \mathrm{~m}^{2} / \mathrm{s}\right)$ as shown in Figure $1211 \mathrm{~b}$, the approximate range of interface growth velocities expected in the melt pools yields a predicted variation in microstructure that closely reflects that observed experimentally. Unfortunately, this set of properties will then tend to under-predict the eutectic spacing, so there are of course interaction effects with other uncertain properties, including the Gibbs-Thomson coefficients, contact angles, and phase diagram information, that may be calibrated to obtain similar effects on the microstructure map. It is outside the scope of the present work to use these results to accurately predict the values of these properties.

While the uncertainty in the inputs renders the microstructure maps shown in Figure 12 11 approximate until more accurate property measurements can be performed, these results may still be used on a qualitative basis to rationalize present results and to guide further research. First, these maps show that the eutectic structure in the Al-Ce system is extremely stable at low interface growth velocities over a wide range of compositions around the eutectic point of Al-10Ce. At higher velocities, a primary dendritic/cellular Al structure becomes stable, and even for compositions rich in Ce, primary intermetallic particles will not form except at very low velocities. This result is consistent with the observations of Sims et al.[6] for the low interface growth velocities found in casting in which no primary intermetallic particles were observed for Al-12Ce, but a reasonable volume fraction was found for Al-16Ce samples. Similarly, for Al-12Ce in this study, no primary intermetallic particles were found. Instead, a eutectic region was present at the outer radius of the melt pools (low interface velocity, high thermal gradients) that 
evolved into a primary $\mathrm{Al}$ structure nearer the center of the pool weld-(high interface growth velocity, low thermal gradient). This observed trend in microstructure is indicated in maps in Figure 1211 by the white arrows.

As an example of using these results to guide future research, Figure $1211 \mathrm{~b}$ suggests that at interface growth velocities not too much higher than those initially tested, a banded $\mathrm{Al}$ structure will be observed. Furthermore, this type of structure is more stable for leaner AlCe compositions. To test the validity of this prediction, one additional laser melt was produced for an Al-8Ce cast plate with a beam velocity of $800 \mathrm{~mm} / \mathrm{min}$ and power of 800 W. Micrographs of the resulting microstructure near the center of the melt pool (where the interface growth velocity is highest) are shown in Figure 13 12. Again, the majority of the microstructure consists of primary $\mathrm{Al}$ dendrites/cells, but some banding is also apparent. The presence of this banded microstructure confirms the qualitative predictions shown in Figure 1211 . The banding observed here, however, is quite different from high velocity banding reported in the literature [23]. Normally, the banded structure alternates between dendritic and planar growth due to oscillations in the interface growth velocity, with complete solute entrapment in the latter structure occurring when the velocity is fastest. In this case however, the bands are cellular/dendritic, but highly aligned compared to the surrounding microstructure. In addition, banding in this material appears to occur at significantly lower velocities than other $\mathrm{Al}$ alloys (about $0.01 \mathrm{~m} / \mathrm{s}$ here compared to about $0.5-0.75 \mathrm{~m} / \mathrm{s}$ in Al-Fe [24], or $0.5 \mathrm{~m} / \mathrm{s}$ in Al-Cu [25]). Similar to traditionally observed banding, the oscillating microstructure here is highly periodic. 
Considering the non-equilibrium nature of the banded microstructure, TEM energy dispersive spectroscopy (EDS) was performed to identify if any significant solute trapping of Ce within the Al matrix occurred during solidification (Figure 14 13). The line scan EDS results in Figure 14 13g show the Ce content in the $\mathrm{Al}$ matrix ranging between approximately 0 and $2 \mathrm{wt} . \%$. Although $2 \mathrm{wt} . \% \mathrm{Ce}$ in the $\mathrm{Al}$ matrix is high compared to the equilibrium partition coefficient (on the order of $10^{-11}$ ), this is within the expected experimental error of this technique. Based on these results, there is no evidence of solute trapping of the Ce within the Al FCC matrix. Further research will be necessary to better understand the nature of this banded microstructure.

\subsection{Opportunities for Optimization of Properties and Microstructure Selection}

Given the above results, there are a variety of opportunities for tailoring the properties and performance of Al-Ce alloys produced via laser additive manufacturing. First, using the microstructure selection map in Figure 1211 as a rough guide, it is possible to tune the amount of eutectic vs dendritic/cellular aluminum that forms within the melt pool as a function of both beam velocity and composition. Alloys higher in Ce will tend to favor eutectic growth, while leaner alloys promote primary Al growth. More significantly, higher interface velocities associated with higher beam velocities promote eutectic growth. At first glance, it seems that it might be difficult to selectively grow a microstructure of primarily eutectic material since only thin layers were found even at low velocities. However, it must be noted that in layer-by-layer additive manufacturing, the previously layer is partially remelted, leaving behind only the outer region of the melt pool. Therefore, even a 
modest thickness of eutectic at the outer edge of the pool as shown in Figure 6 may be enough to result in additively manufactured components that are mostly or completely composed of the eutectic structure. In addition, considering the difficulty in growing primary $\mathrm{Al}_{11} \mathrm{Ce}_{3}$ particles (Figure 1211 ), the quantity of eutectic may be increased by moving to even higher compositions, which would also promote a higher than equilibrium fraction of intermetallic in the coupled growth of the eutectic, tending to increase the overall mechanical properties of the eutectic structure. Furthermore, while changes in beam velocity will obviously affect the interface growth velocity, other process parameters, including pre-heating and scan strategy, are also expected to have a significant effect. Preferentially selecting either primary Al or eutectic growth may be useful to tailor the properties of an additively manufactured component, particularly since mechanical properties are a function of the eutectic spacing. However, the hardness maps produced for this study were not performed at a high enough resolution to quantify the difference in properties between these two microstructure types.

Further changes to the mechanical properties may be accomplished by adding alloying elements into the binary Al-Ce system. Considering the extremely limited solubility for $\mathrm{Al}$ in $\mathrm{Al}_{11} \mathrm{Ce}_{3}$ and $\mathrm{Ce}$ in $\mathrm{Al}$ (Figure 1), the binary system consequently exhibits very little solid solution strengthening. Any alloying element that is soluble in one or both phases would therefore increase the strength of the alloy. Sims et al. [3] used additions of both Mg and Si which resulted in a significant increase in strength in the as-cast condition (and corresponding decrease in ductility) through the present of AlSiCe intermetallic flakes. This alloy also responded more traditionally to a T6 heat treatment producing even higher 
strengths that were competitive with commercial aluminum alloys. The design space offered by selection of composition, process parameters, and heat treatment, will allow for a significant variation in resulting properties.

\subsection{Summary and Conclusions}

The purpose of this study was to validate an alloys evaluation methodology for laser additive manufacturing in which laser melted was used to approximate the solidification conditions present in directed energy deposition (DED). This study evaluated alloy design methodology for AM processes based on existing theories and an Al-Ce alloy using laser melting. The laser power was $800 \mathrm{~W}$, and beam velocities of 100,200 , and $300 \mathrm{~mm} / \mathrm{min}$ were used. The microstructure was evaluated in the as-melted and heat treated state after $24 \mathrm{hrs}$. at $300^{\circ} \mathrm{C}$ in order to assess its stability during high temperature service. The $\mathrm{Al}-\mathrm{Ce}$ exhibited successful melts with no cracking or porosity. The laser melted microstructure was extremely fine in comparison to the cast material due the high solidification rates achieved in laser melting. Interestingly, these fine structures were found to be extremely

stable upon heat treatment. This result suggests that the properties of these alloys will not degrade during high temperature processing or operation. Furthermore, $t$ The structure was observed to transition from eutectic near the outer radius of the melt pool to a primary dendritic/cellular Al structure nearer the centerline. These trends were rationalized by constructing a microstructure selection model based on interface growth theory for rapid solidification. The model made reasonable predictions for the trends in eutectic spacing and changes in microstructure with interface growth velocity. However, due to a lack of 
material property measurements for the Al-Ce system, these predictions have to be considered as only qualitative. The trends in the model predictions were validated through the observation of a banded $\mathrm{Al}$ structure at high velocities $(800 \mathrm{~mm} / \mathrm{min})$ for an $\mathrm{Al}-8 \mathrm{Ce}$ alloy.

\section{Acknowledgements}

This manuscript has been authored by UT-Battelle, LLC under Contract No. DE-AC05000R22725 with the U.S. Department of Energy. The United States Government retains and the publisher, by accepting the article for publication, acknowledges that the United States Government retains a non-exclusive, paid-up, irrevocable, world-wide license to publish or reproduce the published form of this manuscript, or allow others to do so, for United States Government purposes. The Department of Energy will provide public access to these results of federally sponsored research in accordance with the DOE Public Access Plan (<http://energy.gov/downloads/doe-public-access-plan>). This research was sponsored by the Critical Materials Institute, and Energy Innovation Hub funded by U.S. Department of Energy, Office of Energy Efficiency and Renewable Energy, Advanced Manufacturing Office.

\section{Appendix - Model Development}

To determine the relative phase stability for various alloy compositions at a particular interface front velocity, $V$, and thermal gradient $G$, the maximum interface temperature 
approach is used. The fundamental concept is that the interface temperature for each microstructure type is calculated for a given set of conditions and the structure with the highest growth temperature is taken to be the most stable.

\subsection{Eutectic Growth}

The model proposed by Kurz and Trivedi for rapid solidification conditions was used to predict eutectic growth [26]. The general relationships between the eutectic front undercooling, $\Delta T_{E}$, the growth velocity, $V$, and the lamellar spacing, $\lambda$, are taken from the well-known Jackson and Hunt theory [27]:

$\Delta T_{E}=K_{1} \lambda V+\frac{K_{2}}{\lambda}$,

and

$\lambda^{2} V=K_{2} / K_{1}$

The difference in the non-equilibrium case is that the values of $K_{1}$ and $K_{2}$ are a function of non-equilibrium, velocity dependent parameters.

$K_{1}=\frac{m_{E}^{v} C_{0}^{v}}{D} \frac{P}{f_{\alpha} f_{\beta}}$ 
$K_{2}=2 m_{E}^{v}\left(\frac{\Gamma_{\alpha} \sin \theta_{\alpha}}{m_{\alpha}^{v} f_{\alpha}}+\frac{\Gamma_{\beta} \sin \theta_{\beta}}{m_{\beta}^{v} f_{\beta}}\right)$

where $C_{0}^{v}$ is the difference between the non-equilibrium solubilities of the two phases at the eutectic temperature, estimated here using the velocity dependent partition coefficients, $D$ the mass diffusivity in the liquid, $f_{i}$ the volume fraction of a given phase, $\Gamma_{i}$ the Gibbs-Thomson coefficient, $\theta_{i}$ the contact angle of phase $i$ with the liquid, $m_{i}^{v}$ the magnitude of the velocity dependent liquidus slopes, and $m_{E}^{v}$ an average velocity dependent liquidus slope for the eutectic. The liquidus slopes are defined as a function of the velocity dependent partition coefficients:

$m_{i}^{v}=m_{i}\left(1+\frac{k_{i}-k_{i}^{v}\left[1-\ln \left(k_{i}^{v} / k_{i}\right)\right]}{1-k_{i}}\right)$

where $m_{i}$ is the equilibrium liquidus slope for phase $i, k_{i}$ the equilibrium partition coefficient, and $k_{i}^{v}$ the velocity dependent partition coefficient. For the eutectic liquidus slope, the partition coefficients are assumed equal (in this case, the values for $\mathrm{Al}$ are used) and the equilibrium liquidus slope is replaced with an average equilibrium value:

$$
\bar{m}=\frac{m_{\alpha} m_{\beta}}{m_{\alpha}+m_{\beta}}
$$

The non-equilibrium partition coefficient is estimated using the following expression $[28,29]:$ 
$k_{i}^{v}=\frac{\left(k_{i}+P e_{i}\right)}{\left(1+P e_{i}\right)}$,

where the interface Peclet number for solute redistribution is defined as

$P e_{i}=\frac{a_{0} V}{D}$,

and $a_{0}$ is a constant on the order of the interatomic distance.

The value of $P$ in Equation 3 is an infinite series, but was approximated here using the relationship proposed by Kurz and Trivedi [26]:

$P \sim 0.335\left(f_{\alpha} f_{\beta}\right)^{1.65} \xi_{e}$,

where

$\xi_{e}=\frac{2.5 \pi / P e_{E}}{\left[1+\left(2.5 \pi / P e_{e}\right)^{2}\right]^{1 / 2}-1+2 k_{v}}$,

and $P e_{E}$ is the solutal Peclet number for eutectic growth, 
$P e_{E}=\frac{\lambda V}{2 D}$

Again, the calculation of $P$ assumes that the partition coefficients for both phases are equal, and here, the values for $\mathrm{Al}$ are used. The above set of equations is solved iteratively in order to find the dendrite arm spacing and eutectic front interface temperature as a function of the material properties and the interface velocity.

\subsection{Cellular and Dendritic Growth}

Calculations for primary cellular and dendritic growth were performed using the KGT model [17] any by consulting later work by Trivedi and Kurz [30] and Fukumoto and Kurz [31]. For phase $i$, the dendrite tip undercooling, $\Delta T_{i}^{t}$, including non-equilibrium effects, is given as

$\Delta T_{i}^{t}=\left(\frac{k_{i}^{v} \Delta \mathrm{T}_{0}^{v} \operatorname{Iv}(P e)}{1-\left(1-k_{i}^{v}\right) \operatorname{Iv}(P e)}\right)+\left(m_{i}-m_{i}^{v}\right) C_{0}+\frac{2 \Gamma_{i}}{R}+\frac{V}{\mu_{k}}+\frac{G D}{V}$,

where $\Delta \mathrm{T}_{0}^{v}$ is the non-equilibrium freezing range at the nominal composition $C_{0}, \mu_{k}$ the interface kinetic coefficient, Iv is the Ivantsov function, and the length scale for the solutal Peclet number, $P e$, may be taken as the dendrite tip radius, $R$ :

$P e=\frac{R V}{2 D}$. 
The dendrite tip radius is related to the Peclet number, the interface growth velocity, and the thermal gradient by the following expression:

$V\left(\frac{k_{i}^{v} \Delta T_{0}^{v}}{D}\right)\left(\frac{1}{1-\left(1-k_{i}^{v}\right) \operatorname{Iv}(P e)}\right) \xi_{c}-G=\frac{\Gamma_{i}}{\sigma^{*} R^{2}}$

where $\sigma^{*}$ is the dendrite tip selection parameter and the non-equilibrium freezing range may be calculated using

$\Delta T_{0}^{v}=\left(\frac{\Gamma}{\sigma^{*} R^{2}}+G\right)\left(\frac{D\left[-\left(1-k_{i}^{v}\right) \operatorname{Iv}(P e)\right]}{V k_{i}^{v} \xi_{c}}\right)$,

and

$\xi_{c}=1-\frac{2 k_{i}}{\left[1+\frac{1}{\sigma^{*} P e^{2}}\right]^{1 / 2}-1+2 k_{i}^{v}}$

The interface kinetic coefficient is approximated as

$\mu_{k} \approx \frac{V_{0}\left(1-k_{i}\right)}{m_{i}}$,

where $V_{0}$ is approximately the speed of sound in aluminum. The dendrite tip selection parameter, $\sigma^{*}$, affects the calculation of a unique dendrite tip radius. The marginal stability 
model, originally proposed by Langer and Muller-Krumbhaar [32,33], predicts that this value is 0.025 for all systems based on a linear stability analysis and tends to produce reasonable predictions. A more complete model, known as the microsolvability condition $[34,35]$, gives a unique dendrite tip radius when the anisotropy of the interfacial energy is taken into account [36,37]. The dendrite tip selection parameter is no longer a constant in this case, but is instead a function of the interface energy anisotropy parameter [30]. Matters are further complicated by the fact that, as demonstrated by Haxhimali et al. [38] for the Al-Zn system, the anisotropy parameter is a function of alloy composition. That said, the value of $\sigma^{*}$ here has been assumed as 0.025 , consistent with the marginal stability model, but the authors acknowledge that this is an assumption that limits the predictive ability of the present microstructural model.

Once a value of the dendrite tip selection parameter is chosen (or calculated for more rigorous analyses), a unique dendrite tip radius may be calculated:

$R=2 \pi\left[\frac{\Gamma_{i}}{m G_{c} \xi_{c}-G}\right]^{1 / 2}$

The interface concentration gradient in the liquid ahead of the dendrite tip, $G_{c}$, can be calculated from a flux balance at the dendrite tip [30].

$G_{c}=\frac{\left(C_{t}-C_{0}\right) V}{D \operatorname{Iv}(P e)}$ 
where $C_{t}$ is the dendrite tip composition,

$C_{t}=\frac{C_{0}}{1-\left(1-k_{i}\right) \operatorname{Iv}(P e)}$.

The Ivantsov function of the solutal Peclet number, $\operatorname{Iv}(P e)$, is defined as

$\operatorname{Iv}(P e)=P e \exp (P e) E_{1}(P e)$

where $E_{1}$ is the exponential integral, here evaluated using the approximation of Barry, Parlange and Li [39].

\subsection{Banding and Planar Front Growth}

The absolute stability criterion is the velocity, $V_{a}$, at which only planar front growth can exist:

$V_{a}=\frac{D \Delta T_{0}^{v}}{k_{i}^{v} \Gamma_{i}}$

The interface temperature for planar growth, $T_{i}^{p l}$, is given by

$T_{i}^{p l}=T_{m}-\frac{m_{i}^{v} C_{0}}{k_{i}^{v}}-\frac{V}{\mu_{k}}$. 
There is also a region in which banded growth tends to occur, where the planar interface temperature increases with velocity, leading to instabilities between planar and dendritic growth [30].

The above equations are solved numerically using an iterative procedure. The result is a comparison of the interface growth temperature for each microstructure type. The structure with the highest local temperature is the most stable. An example solution is shown in Figure 1514 for the dendrite tip radius of the two possible primary phases (Al and the Al11Ce3 intermetallic) as well as the variation in interface growth temperatures with velocity, all for an Al-12Ce alloy with a thermal gradient of $10^{6} \mathrm{~K} / \mathrm{m}$. To construct the microstructure selection maps, similar solutions were produced for each combination of interface growth velocity, alloy composition, and thermal gradient. The most stable microstructure was recorded in each case in order to produce the plots shown in Figure 12 11.

\section{References}

[1] W.J. Sames, F.A. List, S. Pannala, R.R. Dehoff, S.S. Babu, The metallurgy and processing science of metal additive manufacturing, Int. Mater. Rev. 61 (2016) 315-360. doi:10.1080/09506608.2015.1116649.

[2] T. Mukherjee, J.S. Zuback, A. De, T. DebRoy, Printability of alloys for additive manufacturing., Sci. Rep. 6 (2016) 19717. doi:10.1038/srep19717.

[3] Z.C. Sims, D. Weiss, S.K. McCall, M.A. McGuire, R.T. Ott, T. Geer, O. Rios, P.A.E. Turchi, Cerium-Based, Intermetallic-Strengthened Aluminum Casting Alloy: High-Volume 
Co-product Development, JOM. (2016). doi:10.1007/s11837-016-1943-9.

[4] J.O. Andersson, T. Helander, L. Höglund, P. Shi, B. Sundman, Thermo-Calc \& DICTRA, computational tools for materials science, Calphad Comput. Coupling Phase Diagrams Thermochem. 26 (2002) 273-312. doi:10.1016/S0364-5916(02)00037-8.

[5] W.M. Griffith, R.E. Sanders, G.J. Hildeman, Elevated Temeprature Aluminum Alloys for Aerospace Applications, in: M.J. Koczak, G.J. Hildeman (Eds.), High-Strength Powder Metall. Alum. Alloy., The Metallurgical Society of AIME, Dallas, TX, 1982: pp. 209-224.

[6] Z.C. Sims, O. Rios, S.K. McCall, T. Van Buuren, R.T. Ott, Characterization of Near NetShape Castable Rare Earth Modified Aluminum Alloys for High Temperature Application, in: E. Williams (Ed.), Light Met. 2016, 2016: pp. 111-114.

[7] J.A. Dantzig, M. Rappaz, Solidification, CRC Press, Boca Raton, Fl., 2009.

[8] H. Liao, Y. Sun, G. Sun, Correlation between mechanical properties and amount of dendritic $\alpha$-Al phase in as-cast near-eutectic Al-11.6\% Si alloys modified with strontium, Mater. Sci. Eng. A. 335 (2002) 62-66. doi:10.1016/S09215093(01)01949-9.

[9] E. Rincon, H.F. Lopez, M.M. Cisneros, H. Mancha, Temperature effects on the tensile properties of cast and heat treated aluminum alloy A319, Mater. Sci. Eng. A. 519 (2009) 128-140. doi:10.1016/j.msea.2009.05.022.

[10] ASM Handbook, Volume 02 - Properties and Selection: Nonferrous Alloys and Special-Purpose Materials, in: ASM Handb., ASM International, Materials Park, OH, 1990: pp. 152-177. http://app.knovel.com/hotlink/pdf/id:kt0070VUS4/asmhandbook-volume-02/6si-3-5cu.

[11] W.E. Frazier, Metal additive manufacturing: A review, J. Mater. Eng. Perform. 23 
(2014) 1917-1928. doi:10.1007/s11665-014-0958-z.

[12] H.E. Helmer, C. Körner, R.F. Singer, Additive manufacturing of nickel-based superalloy Inconel 718 by selective electron beam melting: Processing window and microstructure, J. Mater. Res. 29 (2014) 1987-1996. doi:10.1557/jmr.2014.192.

[13] L.L. Parimi, G. Ravi, D. Clark, M.M. Attallah, Microstructural and texture development in direct laser fabricated IN718, Mater. Charact. 89 (2014) 102-111. doi:10.1016/j.matchar.2013.12.012.

[14] R.R. Dehoff, M.M. Kirka, F.A. List, K.A. Unocic, W.J. Sames, Crystallographic texture engineering through novel melt strategies via electron beam melting: Inconel 718, Mater. Sci. Technol. 31 (2015) 939-944. doi:10.1179/1743284714Y.0000000697.

[15] R.R. Dehoff, M.M. Kirka, W.J. Sames, H. Bilheux, A.S. Tremsin, L.E. Lowe, S.S. Babu, Site specific control of crystallographic grain orientation through electron beam additive manufacturing, Mater. Sci. Technol. 31 (2015) 931-938. doi:10.1179/1743284714Y.0000000734.

[16] J. Beuth, J. Fox, J. Gockel, C. Montgomery, R. Yang, H. Qiao, E. Soylemez, P. Peeseewatt, A. Anvari, S. Narra, N. Klingbeil, Process Mapping for Qaulification Across Multiple Direct Metal Additive Manufacturing Processes, Proc. SFF Symp. Austin, TX. 1 (2013) 655-665. doi:10.1017/CB09781107415324.004.

[17] W. Kurz, B. Giovanola, R. Trivedi, Theory of microstructural development during rapid solidification, Acta Metall. 34 (1986) 823-830. doi:10.1016/00016160(86)90056-8.

[18] W. Kurz, R. Trivedi, Eutectic growth under rapid solidification conditions, Metall. Trans. A. 22 (1991) 3051-3057. doi:10.1007/BF02650266. 
[19] W. Kurz, D.J. Fisher, Fundamentals of Solidification, Trans Tech Publications, Switzerland, 1986.

[20] M. Rappaz, B. Carrupt, M. Zimmermann, W. Kurz, Numerical simulation of eutectic solidification in the laser treatment of materials, Helv. Phys. Acta. 60 (1987) 924936.

[21] M. Rappaz, S.A. David, J.M. Vitek, L.A. Boatner, Analysis of solidification microstructures in Fe-Ni-Cr single-crystal welds, Metall. Trans. A. 21 (1990) 17671782. doi:10.1007/BF02672593.

[22] Y.S. Lee, W. Zhang, Modeling of heat transfer, fluid flow and solidification microstructure of nickel-base superalloy fabricated by laser powder bed fusion, Addit. Manuf. In Press (2016). doi:10.1016/j.addma.2016.05.003.

[23] W. Kurz, R. Trivedi, Banded solidification microstructures, Metall. Mater. Trans. A. 27 (1996) 625-634. doi:10.1007/BF02648951.

[24] M. Gremaud, M. Carrard, W. Kurz, The Microstructure of Rapidly Solidified Al-Fe Alloys Subjected to Laser Surface Treatment, Acta Met. Mater. 38 (1990) 2587-2599.

[25] M. Zimmermann, M. Carrard, W. Kurz, Rapid solidification of Al-Cu eutectic alloy by laser remelting, Acta Metall. 37 (1989) 3305-3313. doi:10.1016/00016160(89)90203-4.

[26] R. Trivedi, P. Magnin, W. Kurz, Theory of eutectic growth under rapid solidification conditions, Acta Metall. 35 (1987) 971-980. doi:10.1016/0001-6160(87)90176-3.

[27] K.A. Jackson, J.D. Hunt, Lamellar and rod eutectic growth, AIME Met Soc Trans. 236 (1966) 1129-1142.

[28] M.J. Aziz, Model for solute redistribution during rapid solidification, J. Appl. Phys. 53 
(1982) 1158-1168. doi:10.1063/1.329867.

[29] M.J. Aziz, T. Kaplan, Continuous Growth Model for Interface, Acta Metall. Mater. 36 (1988) 2335-2347. doi:10.1016/0001-6160(88)90333-1.

[30] R. Trivedi, W. Kurz, Dendritic Growth, Int. Mater. Rev. 39 (1994).

[31] S. Fukumoto, W. Kurz, The $\delta$ to $\gamma$ transition in Fe-Cr-Ni alloys during laser treatment, ISIJ Int. 37 (1997) 677-684. doi:10.2355/isijinternational.37.677.

[32] J.S. Langer, J. Muller-Krumbhaar, Stability effects in dendritic crystal growth, J. Cryst. Growth. 42 (1977) 11-14. doi:10.1016/0022-0248(77)90171-3.

[33] J.S. Langer, H. Muller-Krumbhaar, Theory of dendritic growth-I. Elements of a stability analysis, Acta Metall. 26 (1978) 1681-1687. doi:10.1016/00016160(78)90078-0.

[34] D.I. Meiron, Selection of steady states in the two-dimensional symmetric model of dendritic growth, Phys. Rev. A. 33 (1986) 2704-2715.

[35] A. Barbieri, D.C. Hong, J.S. Langer, Velocity selection in the symmetric model of dendritic crystal growth, Phys. Rev. A. 35 (1987) 1802-1808. doi:10.1103/PhysRevA.35.1802.

[36] D.A. Kessler, H. Levine, Stability of dendritic crystals, Phys. Rev. Lett. 57 (1986) 3069-3072. doi:10.1103/PhysRevLett.57.3069.

[37] D. Bensimon, P. Pelce, B.I. Shraiman, Dynamics of curved fronts and pattern selection, J. Phys. 48 (1987) 2081-2087. doi:10.1051/jphys:0198700480120208100.

[38] T. Haxhimali, A. Karma, F. Gonzales, M. Rappaz, Orientation selection in dendritic evolution, Nat. Mater. 5 (2006) 660-664. doi:10.1038/nmat1693.

[39] D.A. Barry, J.-Y. Parlange, L. Li, Approximation for the exponential integral (Theis well 
function), J. Hydrol. 227 (2000) 287-291. doi:10.1016/S0022-1694(99)00184-5. 


\section{Figure Captions}

Figure 1: The binary Al-Ce phase diagram calculated using computational thermodynamics.

Figure 2: Sensitivity analysis of eutectic spacing relative to a variety of input parameters showing the change in eutectic spacing as a fraction of the mean value for a $\pm 10 \%$ change in a given input. An interface growth velocity of $200 \mathrm{~mm} / \mathrm{min}$ was used. The nominal eutectic spacing was $0.463 \mu \mathrm{m}$ for values given in Table 2 .

Figure 3: Optical micrographs of weld cross-sections for each velocity.

Figure 4: Comparison of as-cast and laser weld microstructural length scales for a beam velocity of $100 \mathrm{~mm} / \mathrm{min}$.

Figure 5: Higher magnification view of differences in microstructure at different points in the weld pool for the three beam velocities.

Figure 6: Depth of eutectic region at the edge of the weld pool as a function of beam velocity, distance shown is from edge of weld pool to the beginning of unstable eutectic growth.

Figure 7: Microstructure of laser melted samples after heat treatment at $300^{\circ} \mathrm{C}$ for $24 \mathrm{hrs}$. 
Figure 8: Directc-Comparison of Al-12Ce laser melted with $800 \mathrm{~W}$ and beam velocity of 300 $\mathrm{mm} / \mathrm{min}$ showing difference in the microstructure length scale between the laser melted and cast structure and no significant microstructural coarsening after heat treatment.

Figure 9: (a) Vickers hardness map for the as-melted conditions with a beam velocity of $200 \mathrm{~mm} / \mathrm{min}$, (b) the corresponding hardness map with the same beam velocity after a 24 hour heat treatment at $300^{\circ} \mathrm{C}$, and (c) SEM micrographs of the as-melted sample showing the location of indents relative to the melt pool and indents with very low hardness due to local porosity in the cast microstructure.

Figure 10 9: Histograms showing the distribution of Vickers hardness measurements for the (a) as-melted and (b) heat-treated conditions.

Figure 11 10: Comparison of eutectic spacing between the microstructural theory and experimental results. Experimental data is taken from both the as-melted and heat treated conditions. Horizontal error bars show the variation in velocity between an interface moving parallel to the beam and at a $45^{\circ}$ angle and vertical error bars indicate two standard deviations above and below the mean values. Model results are shown for $\mathrm{Al}-\mathrm{Ce}$ with estimated properties given in Table 2 as well as a comparison to the predicted eutectic spacing for Al-Si under the same conditions. The mass diffusivity used for Al-Ce was $10^{-9}$ $\mathrm{m}^{2} / \mathrm{s}$.

Figure 12 11: Microstructure selection map in composition vs. velocity space for an assumed thermal gradient of $10^{6} \mathrm{~K} / \mathrm{m}$ for mass diffusivities of (a) $10^{-9} \mathrm{~m}^{2} / \mathrm{s}$ and (b) $10^{-10}$ 
$\mathrm{m}^{2} / \mathrm{s}$. The white arrow shows an approximation of the microstructural path observed within the weld pools.

Figure 13 12: Slight banding at high velocities and lower Ce content for an Al-8Ce melted with a laser power of $800 \mathrm{~W}$ and a beam velocity of $800 \mathrm{~mm} / \mathrm{min}$ showing (a) several bands near the center of the weld pool and (b) a higher magnification of a single band (artificially colored for clarity).

Figure 14 13: (a) BF-STEM and (b) HAADF-STEM images of the Al-8Ce alloy processedat $800 \mathrm{~W}$ with a beam velocity of $800 \mathrm{~mm} / \mathrm{min}$ with EDS elemental maps for (c) $\mathrm{Al}$ and (d) Ce and EDS point spectra from (e) Al-rich region (EDS 1), (f) Ce-rich region (EDS 2), and (g) EDS line profile generated across Ce-rich region given in wt.\% Ce.

Figure 15 14: Example of results from the microstructure selection model showing (a) the dendrite tip radii and (b) interface growth temperatures for an Al-12Ce alloy with a thermal gradient of $10^{6} \mathrm{~K} / \mathrm{m}$. 


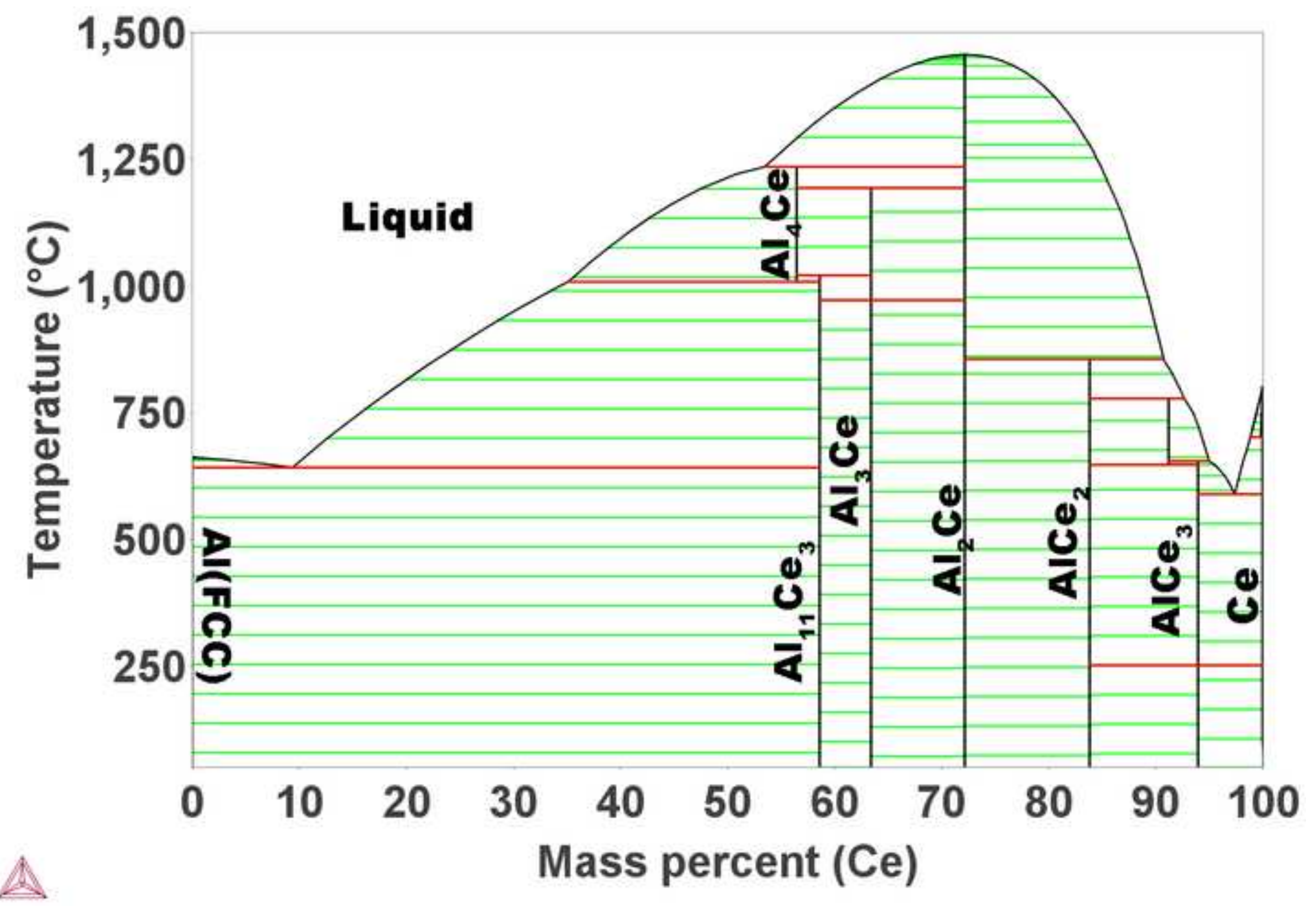




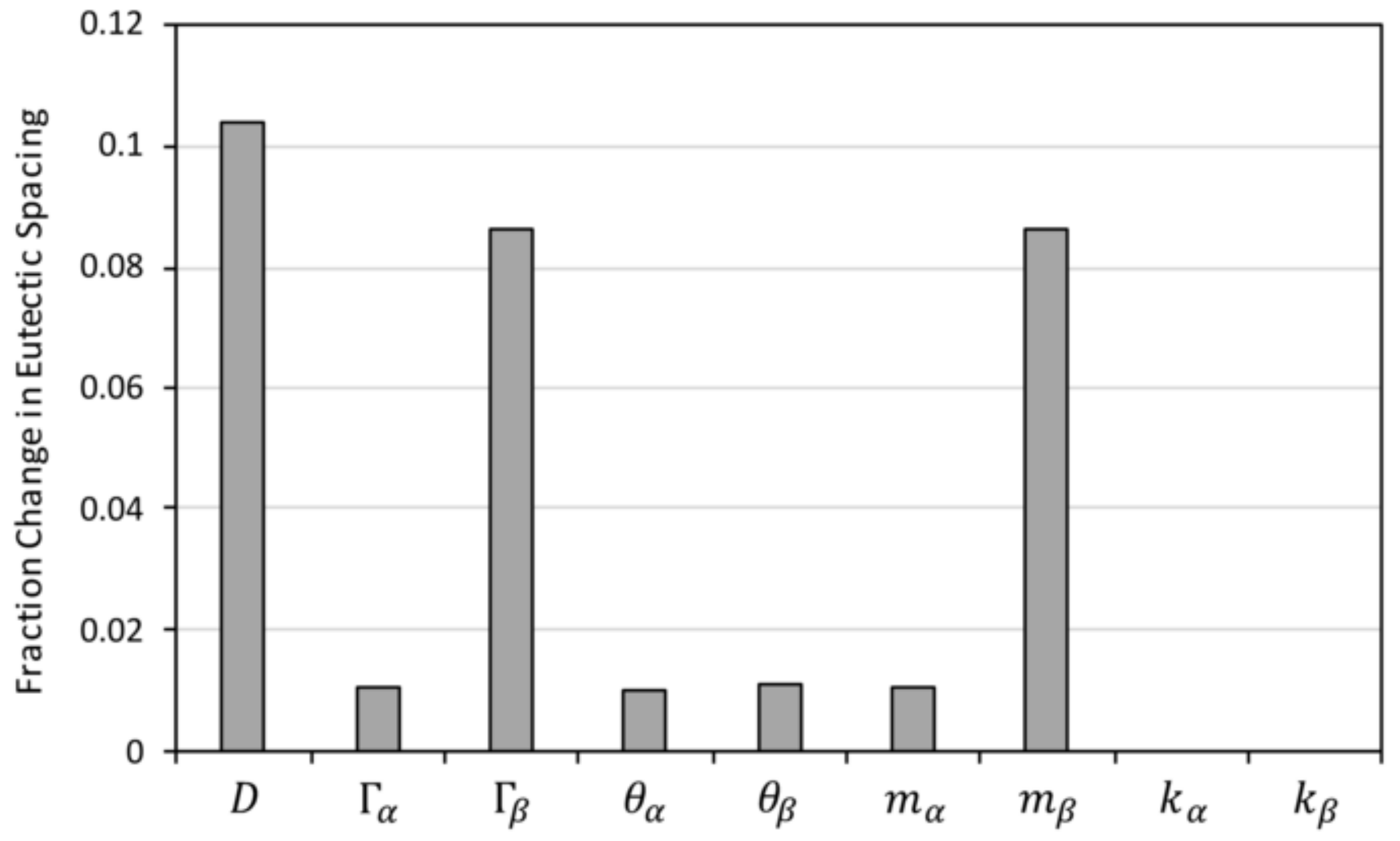


$100 \mathrm{~mm} / \mathrm{min}$

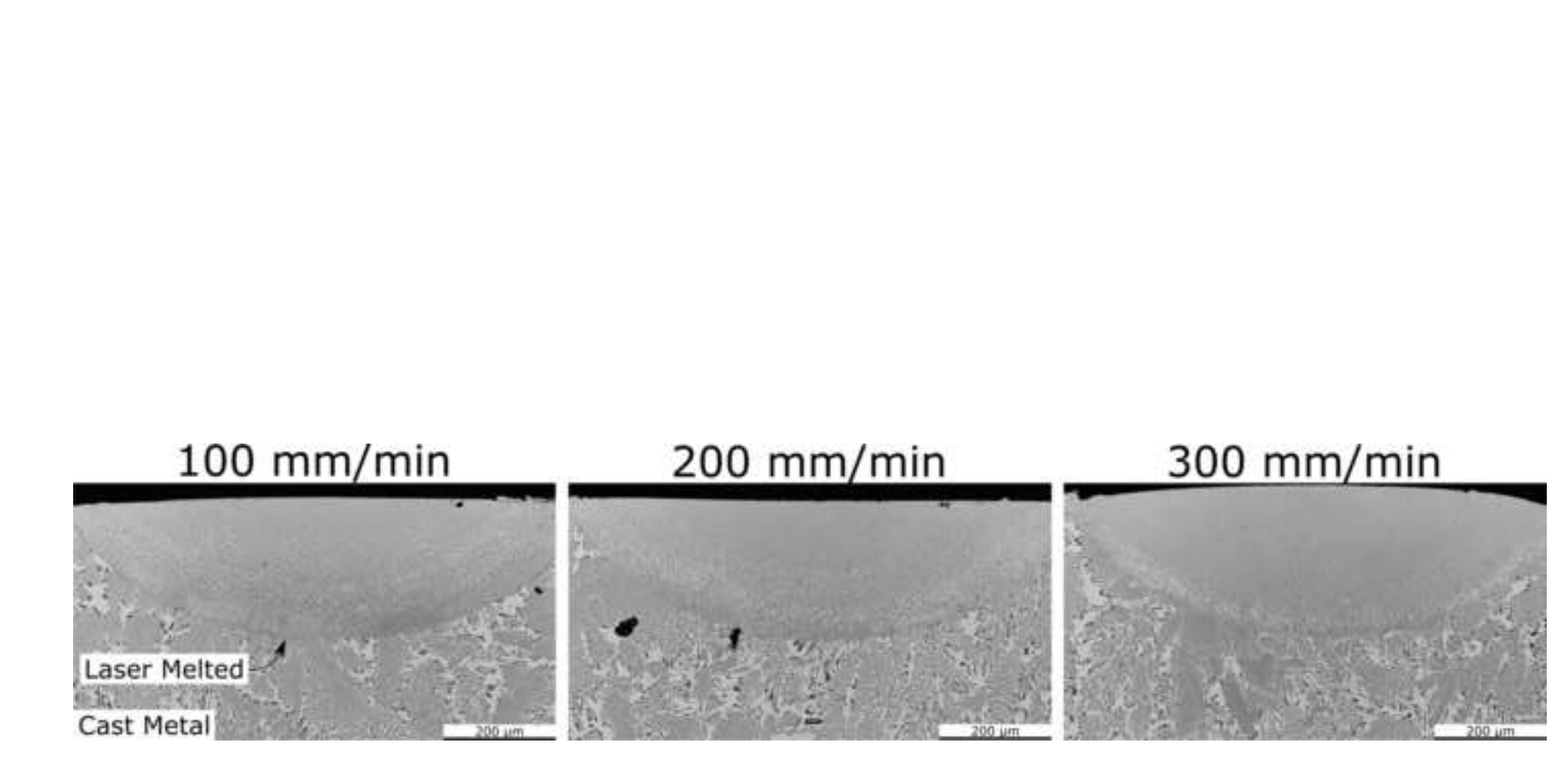

$200 \mathrm{~mm} / \mathrm{min}$

$300 \mathrm{~mm} / \mathrm{min}$

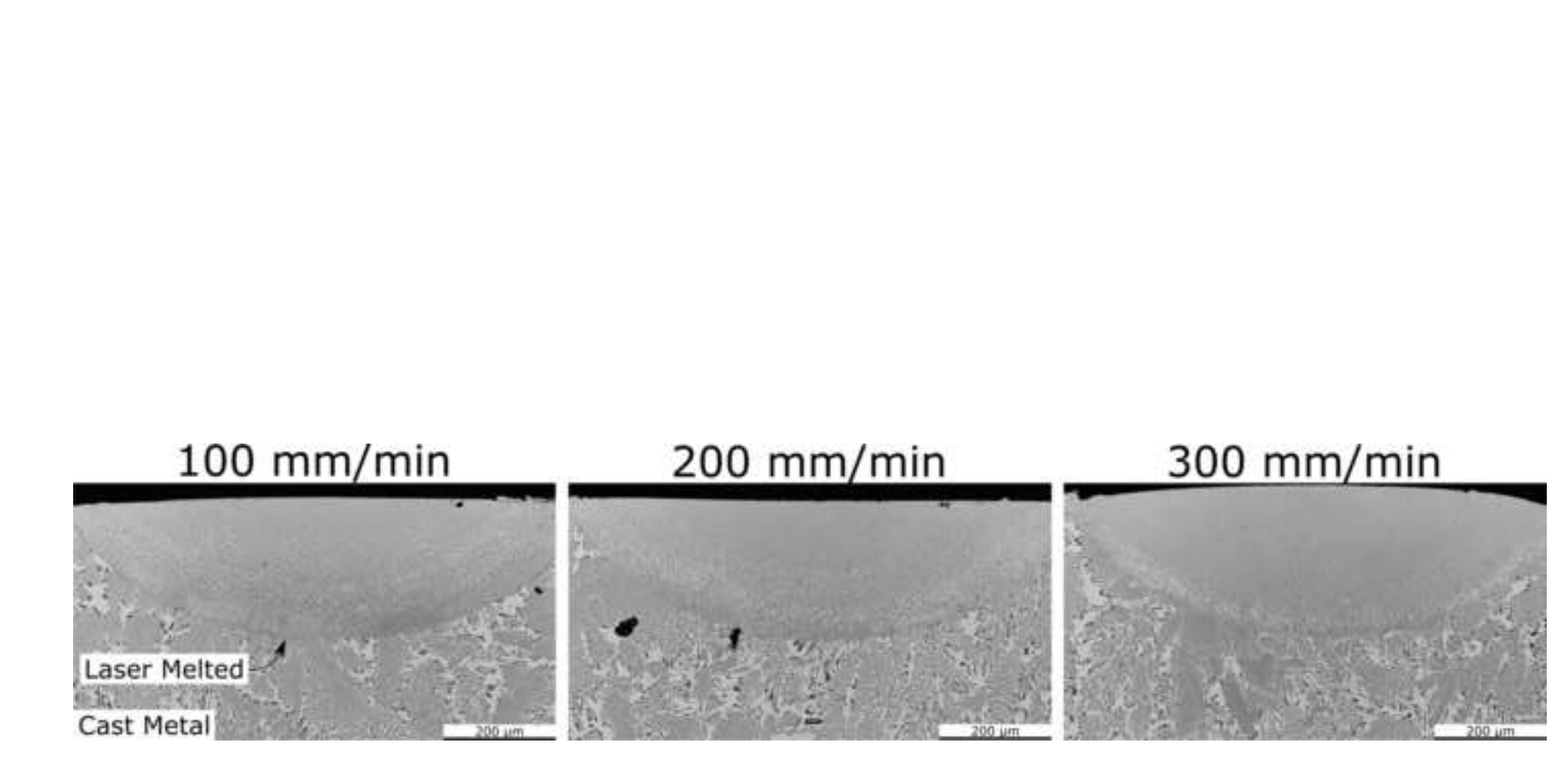

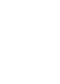




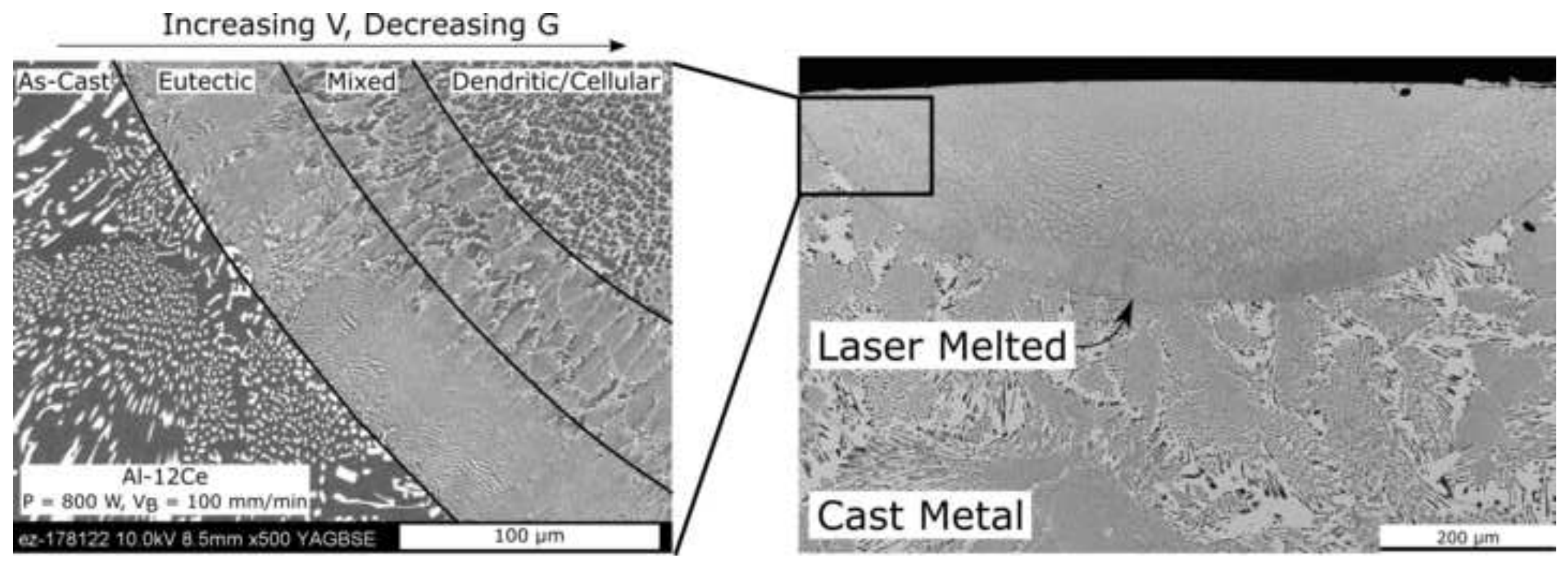




\section{Near edge of weld pool}

All eutectic
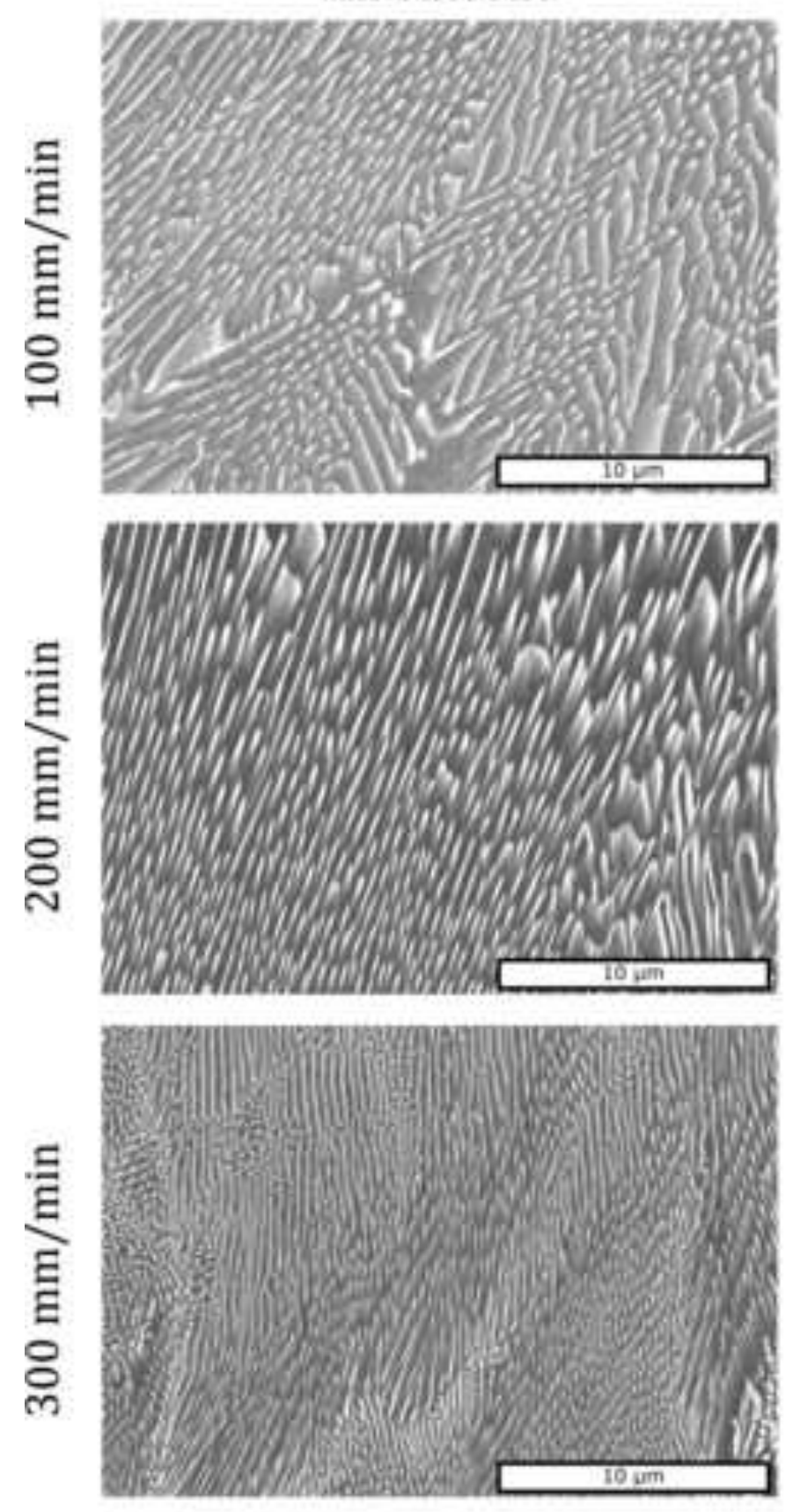

Further from edge of pool

Instabilities in eutectic growth
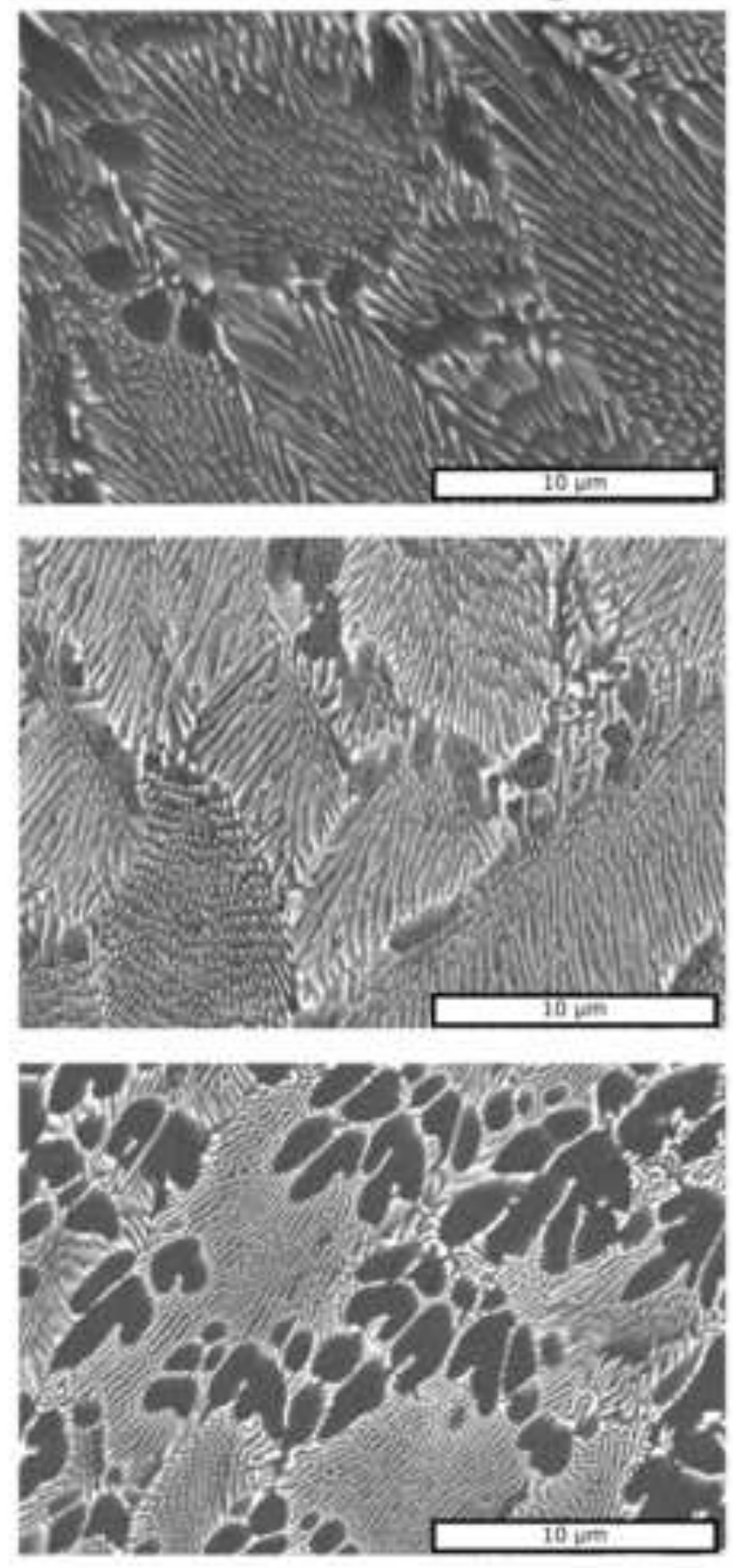

Center of pool

Dendritic/cellular

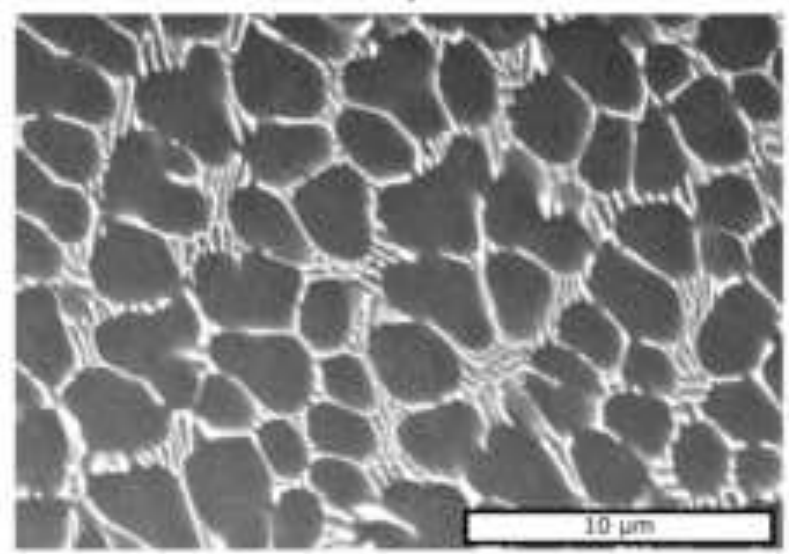

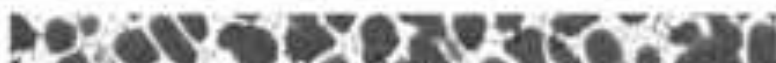
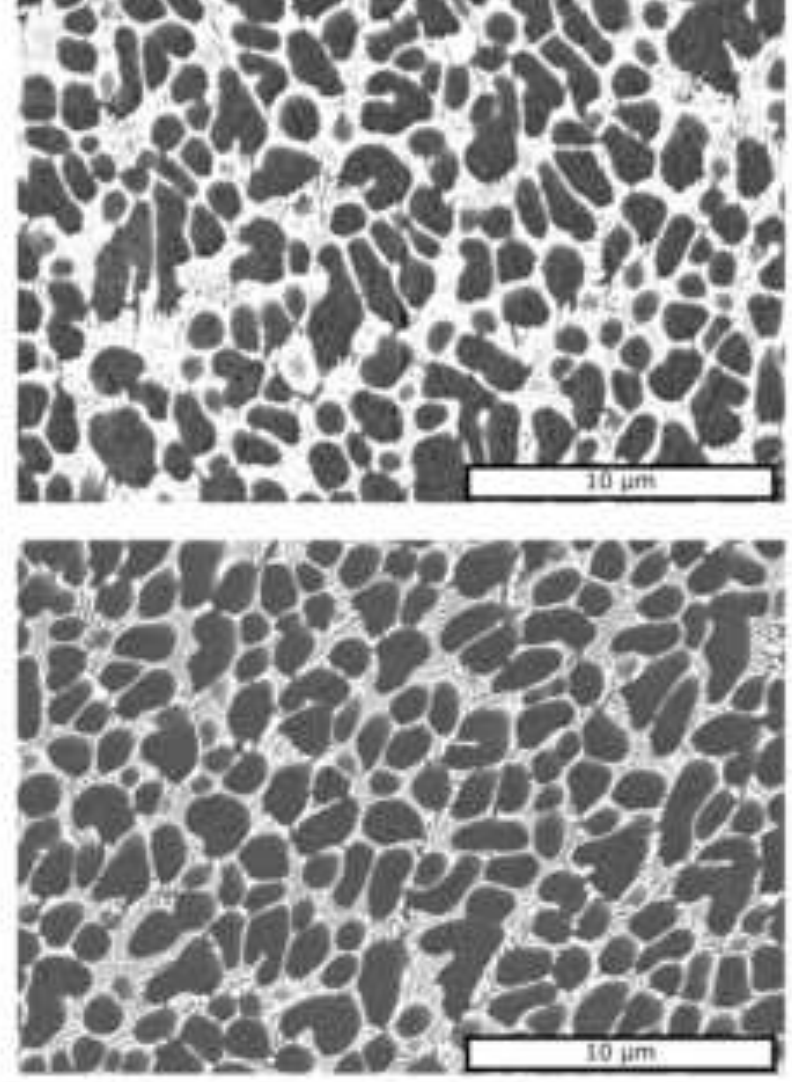
Near edge of weld pool All eutectic
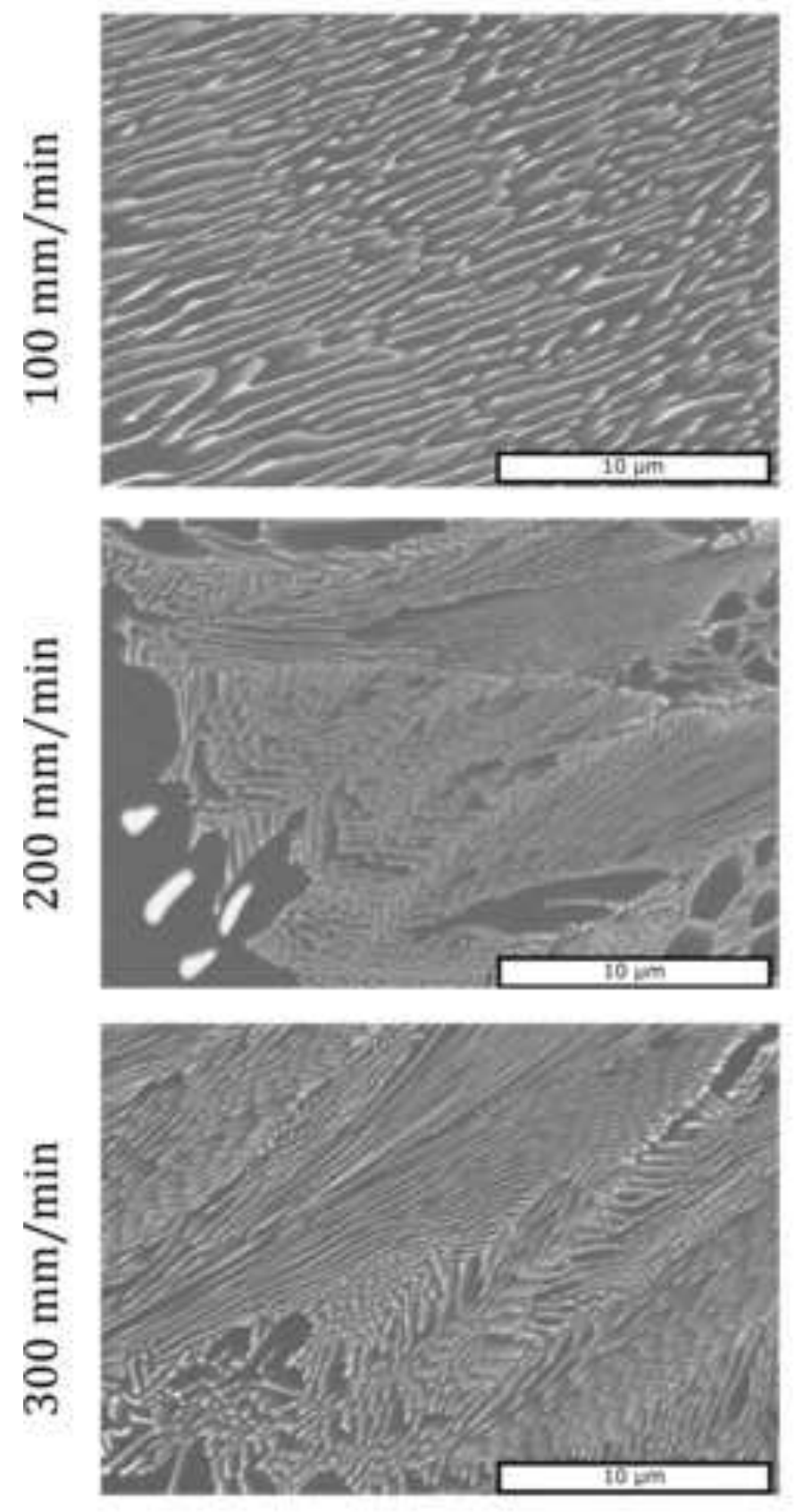

Further from edge of pool Instabilities in eutectic growth
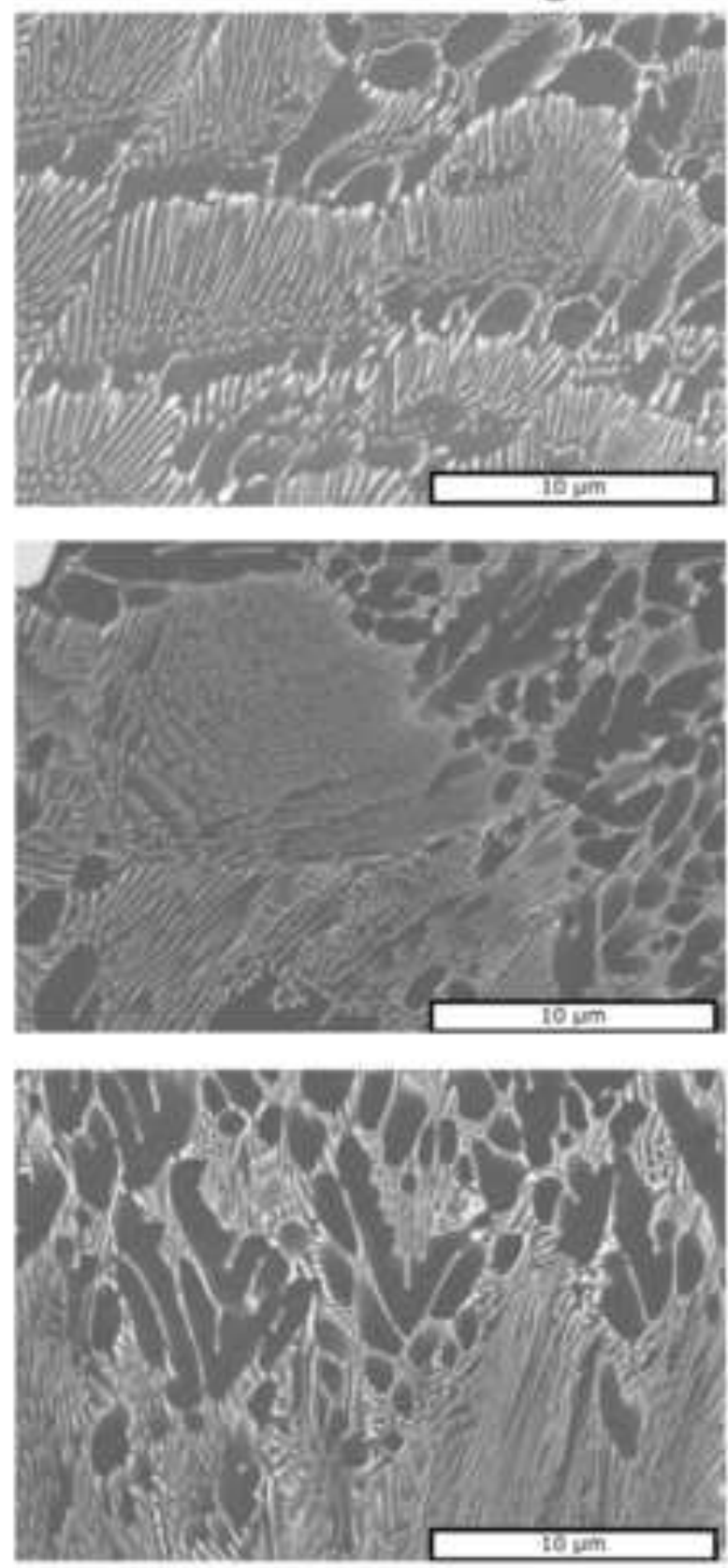

Center of pool

Dendritic/cellular
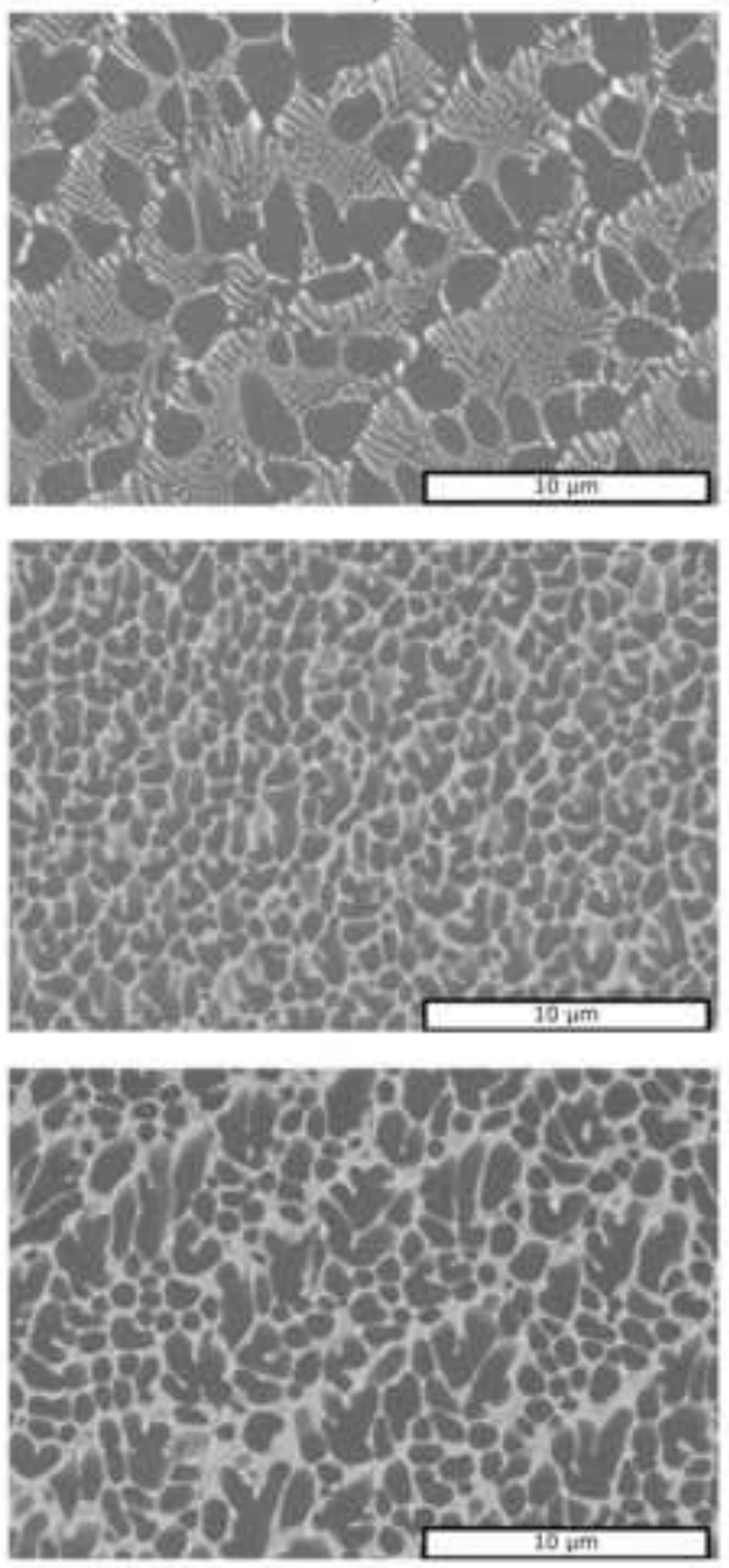

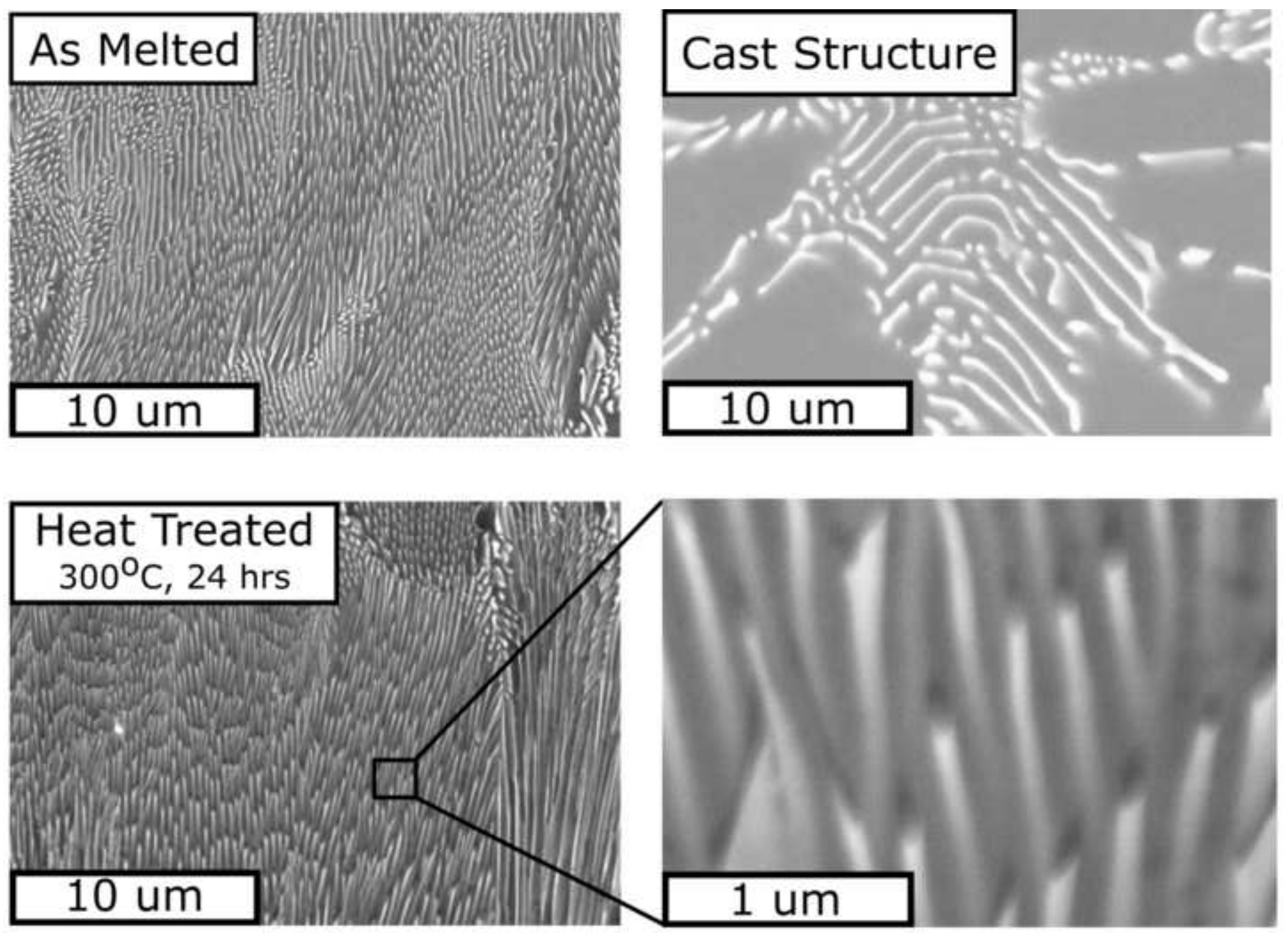

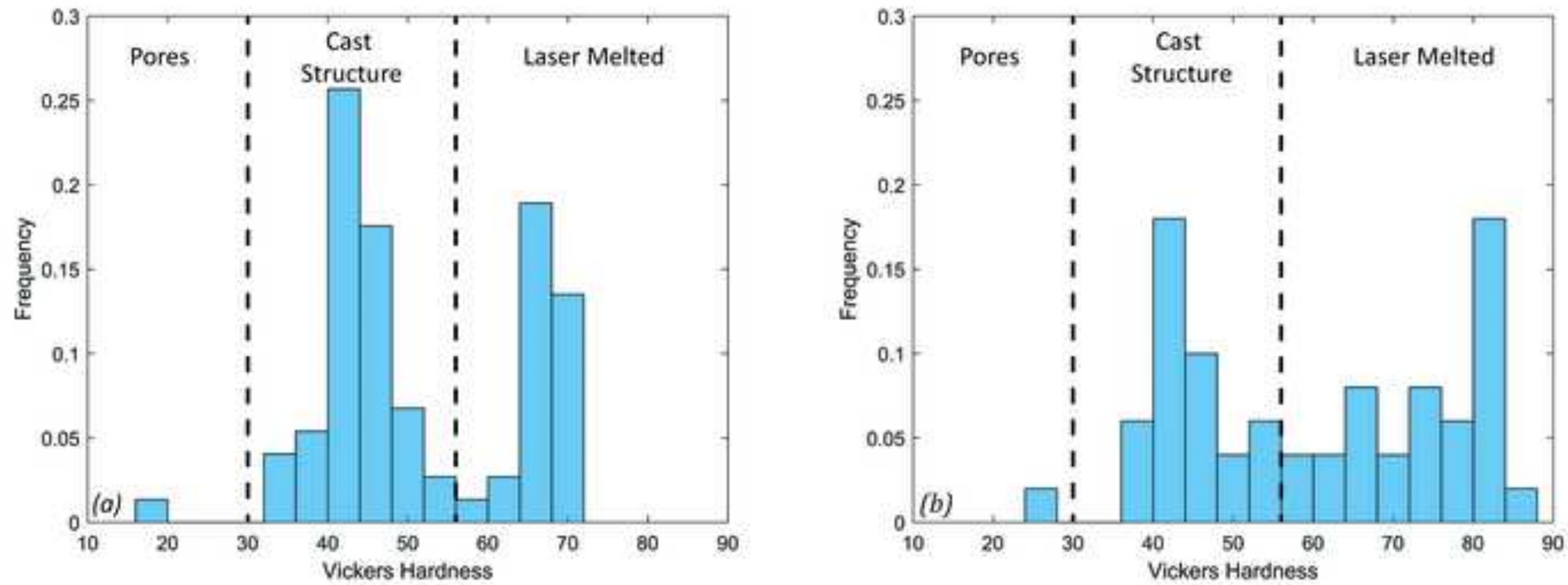


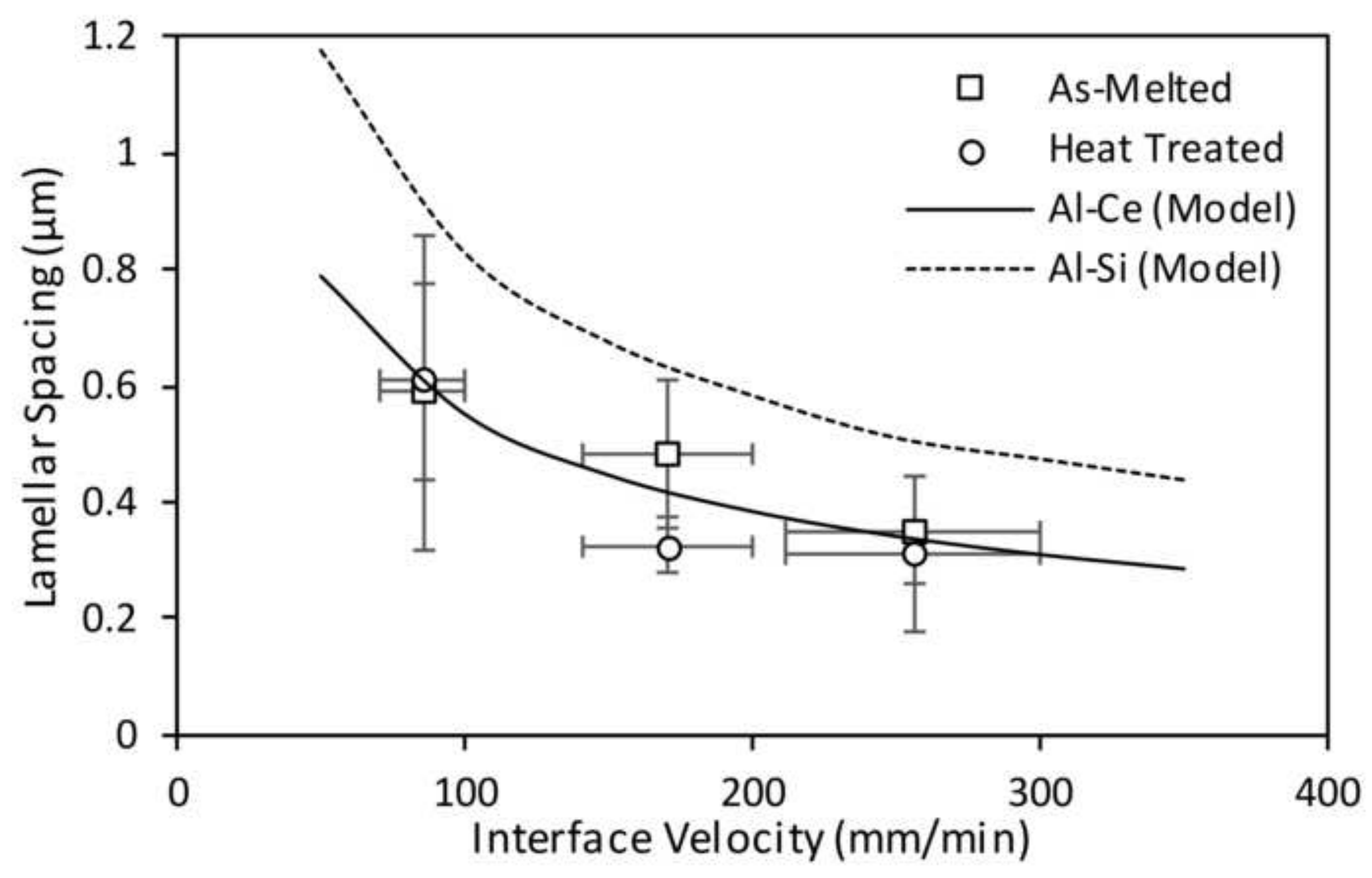



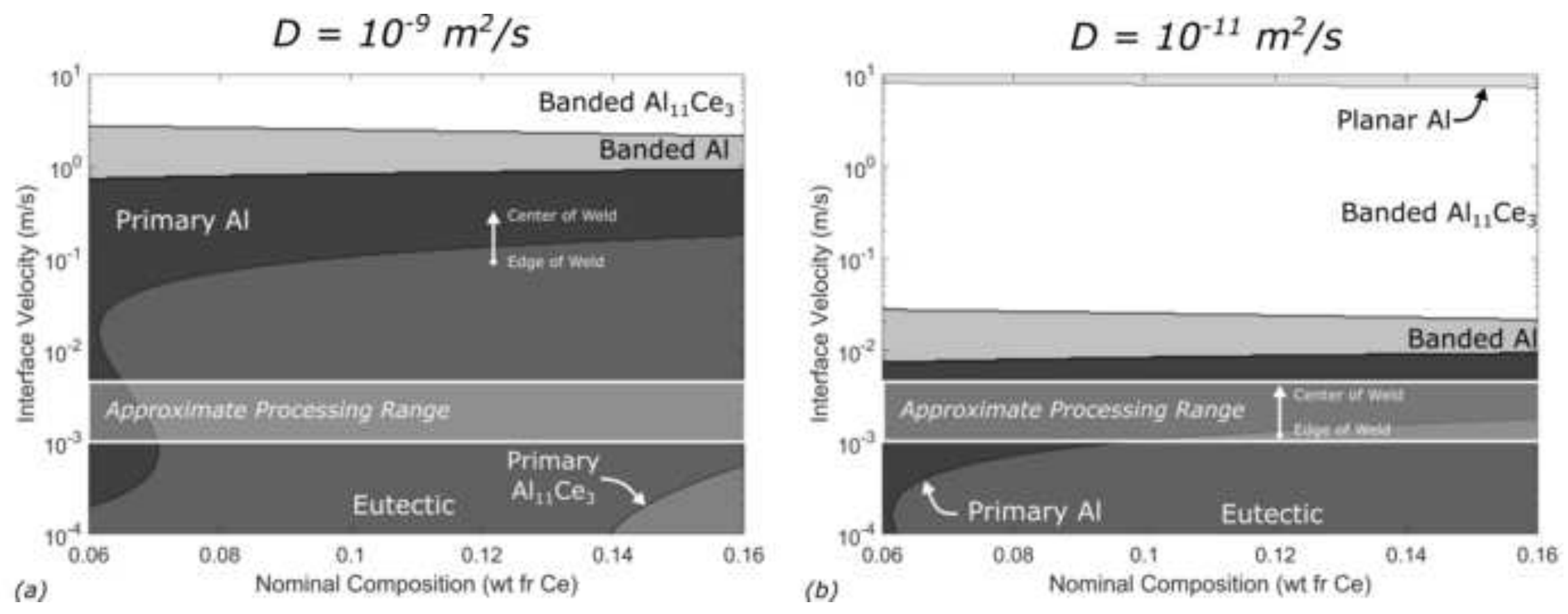

Figure 11

(a)

(b) 


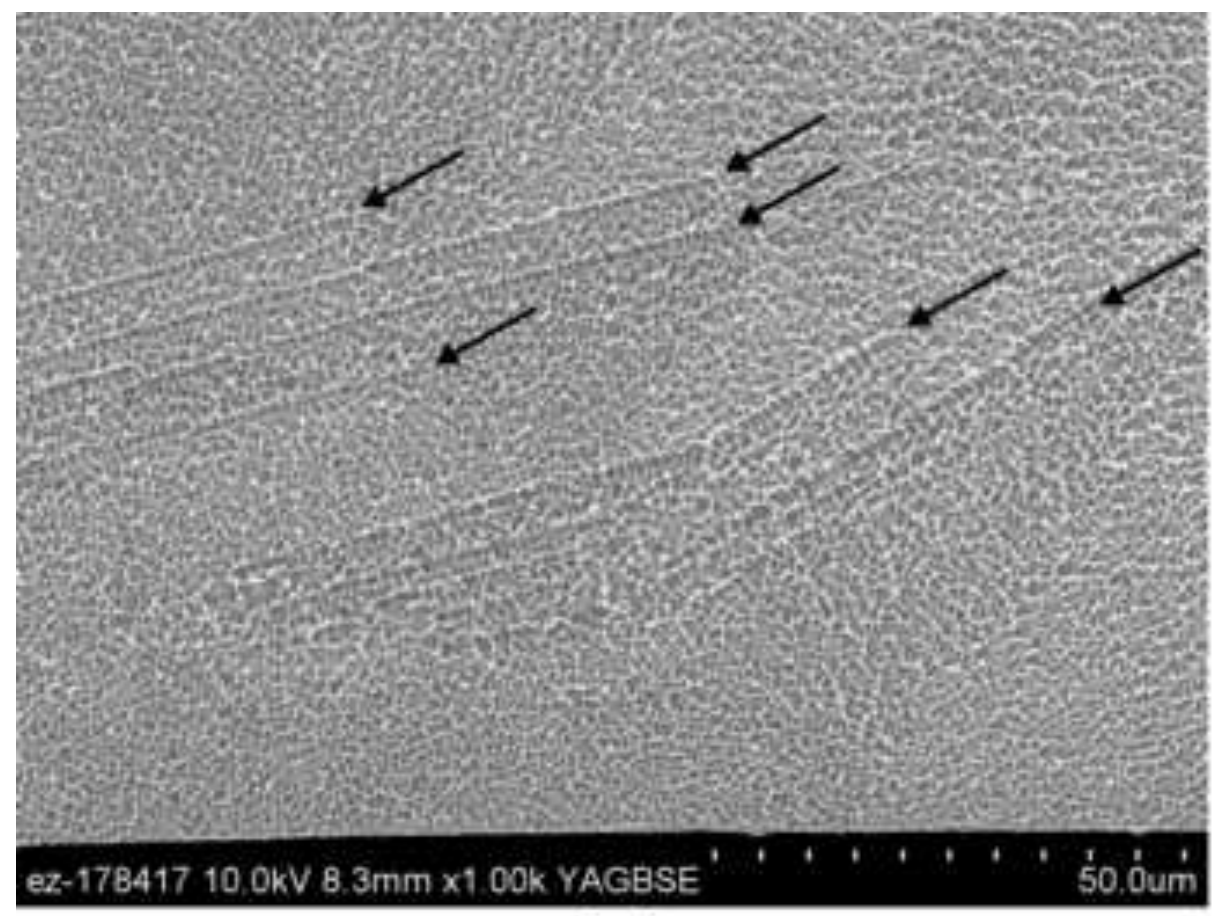

(a) (a)

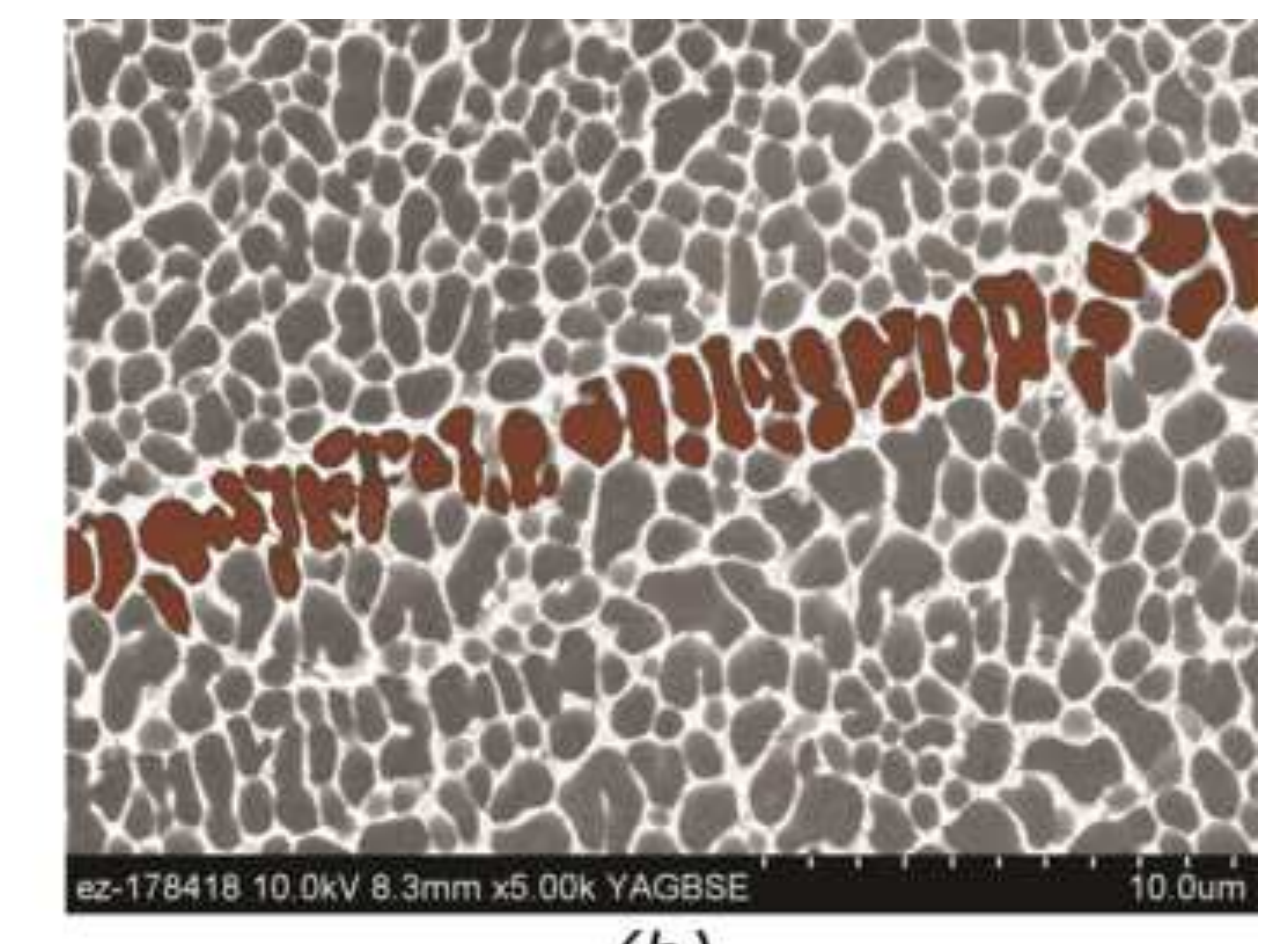

(b) . 


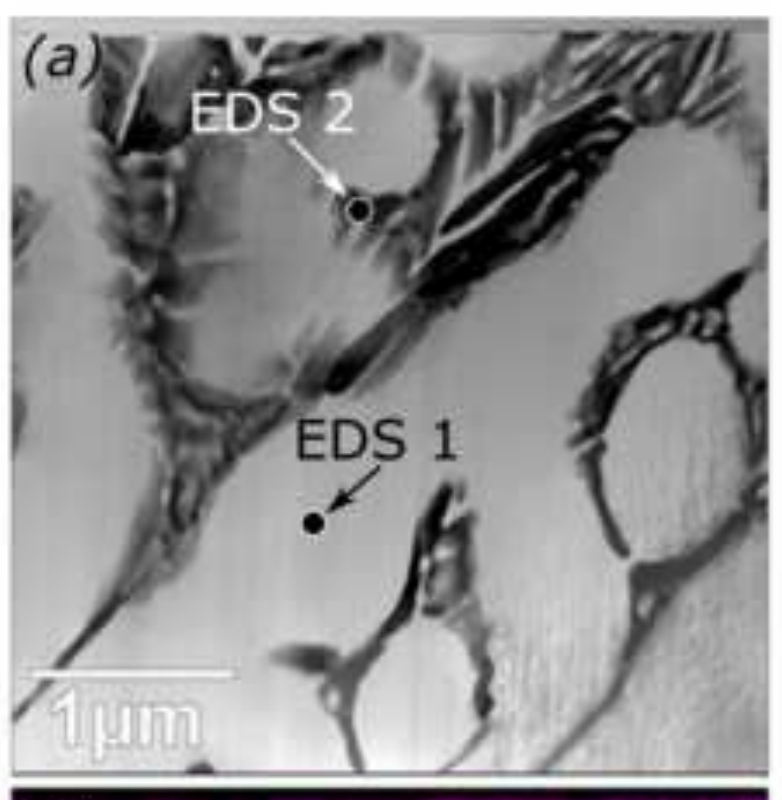

(c)

Al
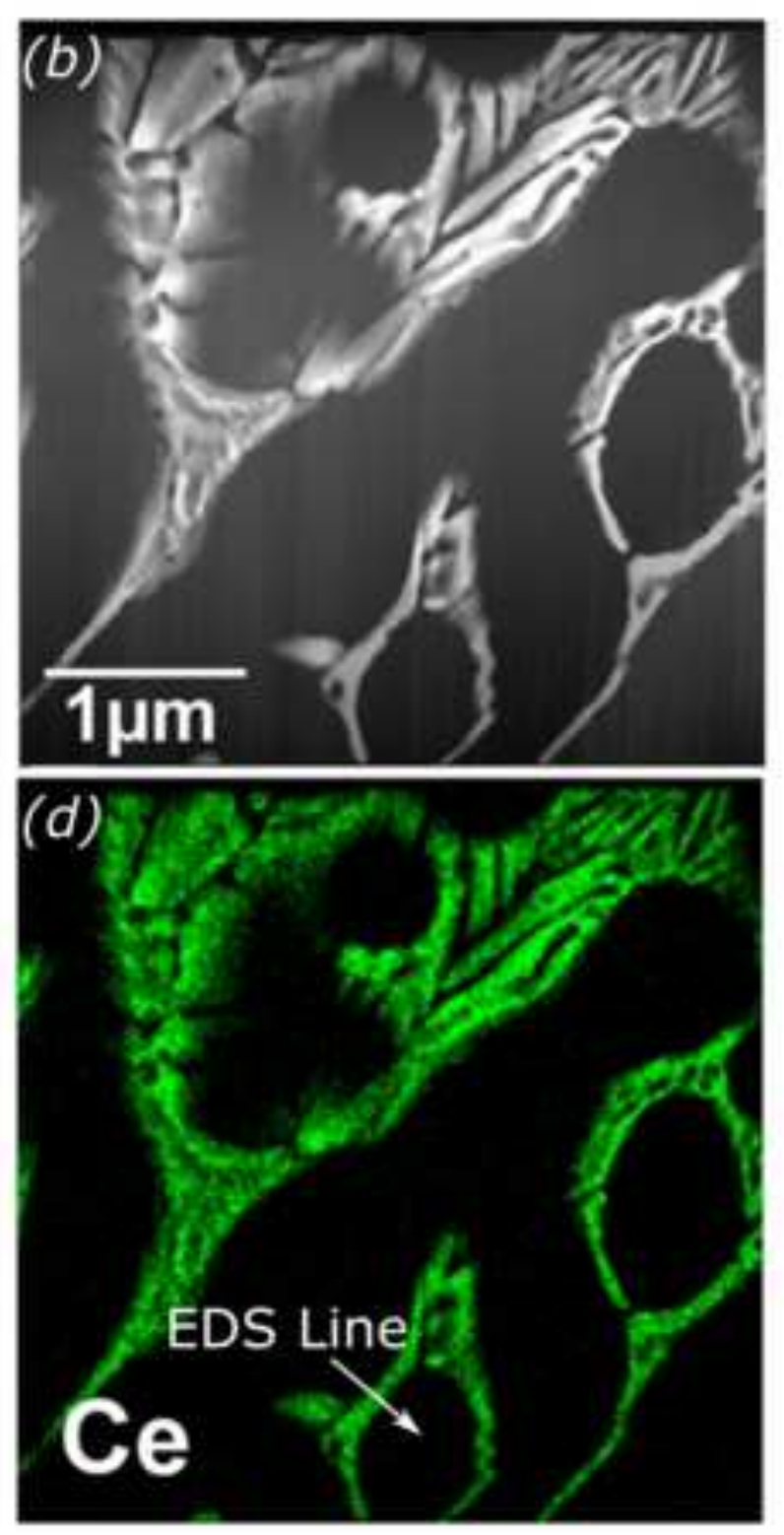

(e)

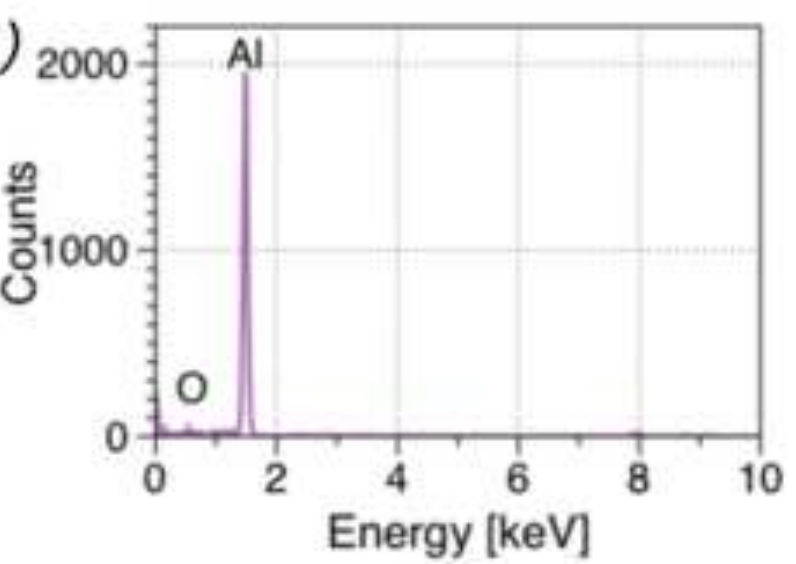

(f)

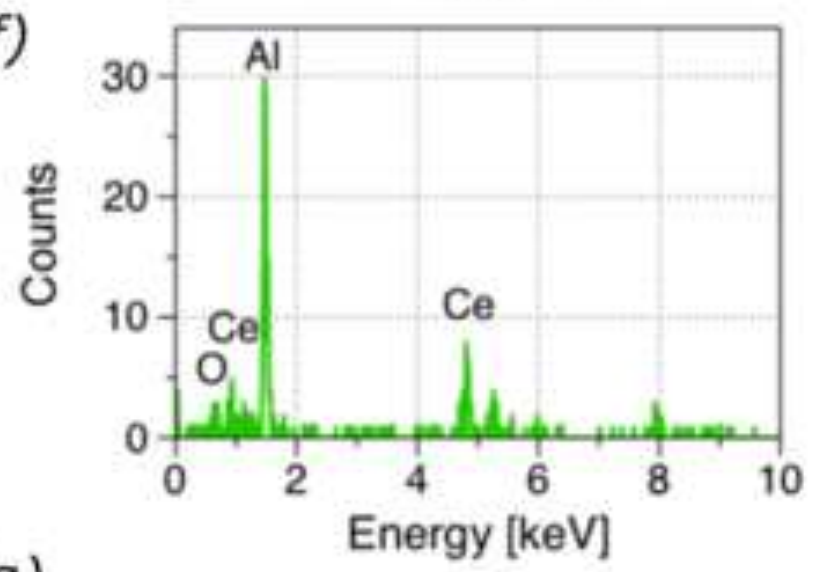

(g)

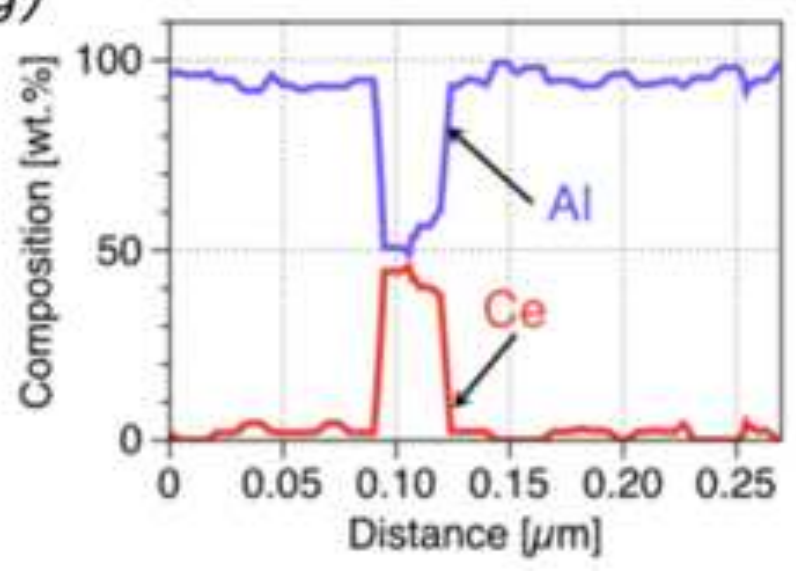




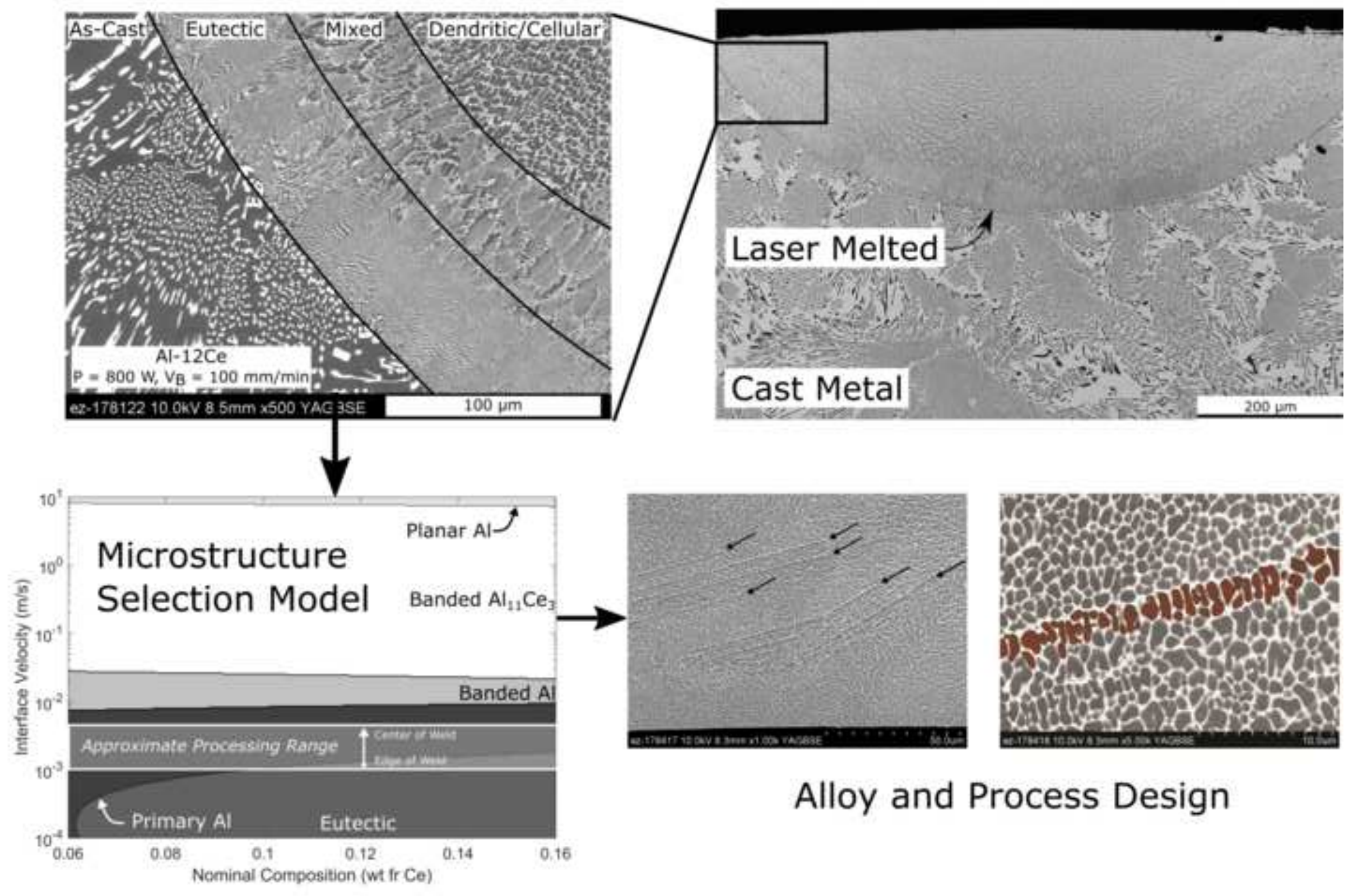

